\title{
الفجاءة في التصوير التشبيهي في نهج البلاغة دراسة أسلوبية
}

Surprise in simulated photography In the approach of rhetoric Stylistic study $\square$

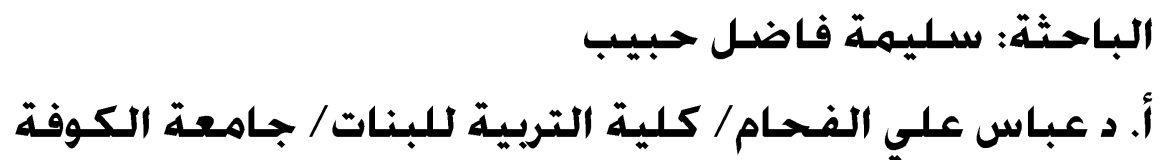

$\underline{\text { Abstract }}$

What leads us to study the surprise in artistic photography in the approach of Balagha, the attachment between the picture and the meaning and the shadows of that image, which can be applied to the recipient in the case of the manifestation of meaning and appearance, or the ability to produce several images contributes to the richness of meaning, This is in line with the stylistic vision that the nderstanding of the graphic image stems from the fact that it is an upscale adoption of the procedure of turning away from the ordinary language and searching for the meaning of the image. Means of detecting meanings in other ways, accompanied by the fun that intersperses the stages of the disclosure of the meaning of the creation of spaces and distances tense that stop the recipient and challenge to fill, not to mention that the pleasure offered by the ablution, including the potential to overcome the barriers Boolean, which is the first stimulant of the recipient's attention.

Key words: Surprise. Approach. Rhetoric

|لغالإن

إنّ ممّا يحدونـا إلى دراسة الفُجاءة في التَّصوير الفنّيّ في نهج البلاغة ذلك التُعُّق الذي يحصل بين الصُّورة والمعنى وبين ظلال تلك

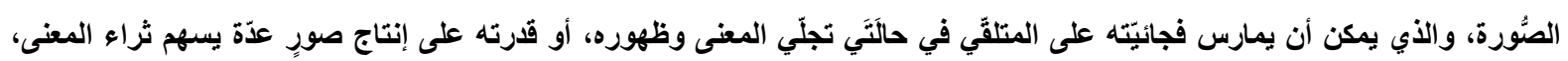
وجودته في تثكّلها .وتكمن الفُجاءة في ذلكك بقدة المُبدع - بما يملكه من قرة إبداعيّة في التّصوير- على إنتاج ألفاظ وتراكيب تخرج معانيها ودلالاتها عن دائرة تصوّر المتلقّي وتوقِّاته، وهو ما يتوافق والروئة الأسلوبيّة في أنّ فهم الصُّورة البياتيّة ينطلق من كونها ذلك التبنّي

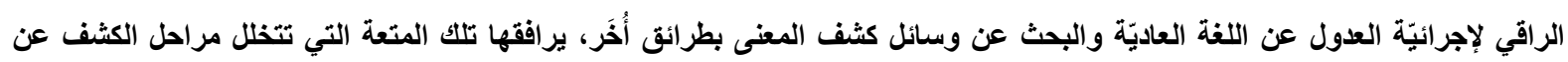

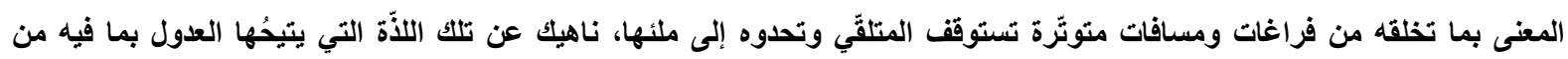
إمكانات تتعلّق بتجاوز الحواجز المنطقيّة ، التي تعدّ المثير الأوّل لانتباه المتلقيّي

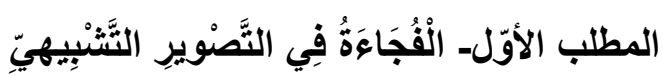

عُرِّفت التَّنبيه بأنّه عمليَّة مقارنة بين طرفين: مشبّه ومشبّهَه به لعلاقة تجمع بينهما'، إلّا أنّ قيمة التَّبيه

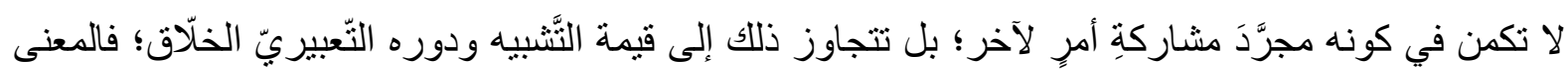
في التشبيه الفنيّ ليس مجرّدَ علاقة أو فكرة سابقة على صورته؛ بل هو مجموعة الإيحاءات، و الدلالات الفنيّة الخالصة التي لا توجد إلّا بوجود تلك الصُّورة، ولا تنبثق إلّا في شكلها اللغويّ الخاصّ؛ فالصورة الفنيّة وسيلة

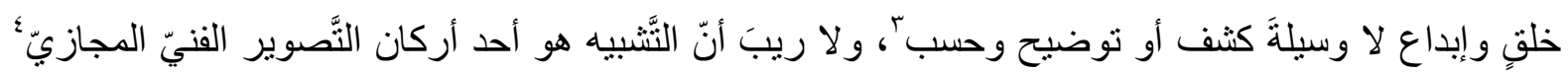
الذي يضطلع به النصّ يلجأ إليه المنشئ كثيرًا؛ ليمبطَ اللثامَ عن فكرةٍ ما مقصودة من خلال هذا الأسلوب بحيث لا يكون الغرض من التشبيه تشبيه شيءٍ بشي؛ٍ؛ ليدلَّ على حصول صفة المشبّه به في المشبّه؛ وحسب، و إنّما لإيصال المتلقيّ إلى معرفة وجه العلاقة القائمة بين طرفي التّّبيه لإرساء صورة معيّنة لقضيّة معيّنة في نفيّيّة

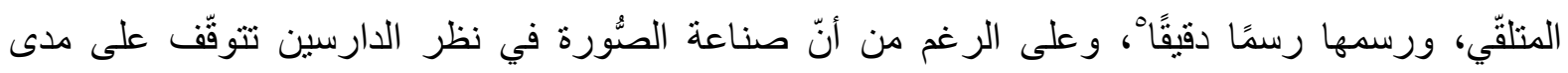


التَّوفيق بين طرفيه المشبّه والمشبّه به على اعتبار وجود تثابه منطقيّ بين الطَّرَفين، إلّا أنّ من الدراسات ما

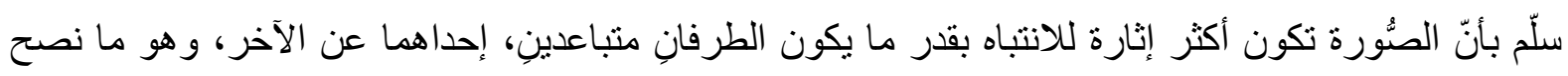

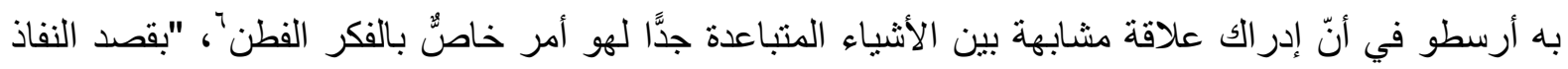

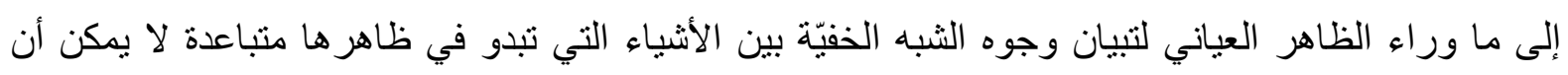
تصلح صورة تثبيهيّة، وعلى مدى ما يضاف ويؤلّف ويركّب من تلك الأطر اف تتِّح الصُّورة الأصيلة،

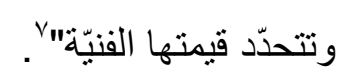

وقدٌ أكّد البلاغيون العربُ ضرورة التّفاعُل بين طرفي الصُّورة التشبيهيَّة "و التفاعل بين طرفَي الصورة

لا يتحقّق على مدى تحقُّ الصفات المشتركة بينها على نحو الحقيقة والواقع؛ بل إنّ المبدع بما أوتي من بقظة عقليَّة وحسِّ مُر هف بإمكانه أن يكتشف وجهًا من وجوه الثَّبَه للرَّبط بين طرفي الصورة التشبيهيّة وتفاعلها على مدئ

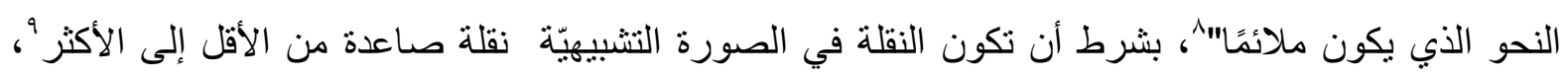

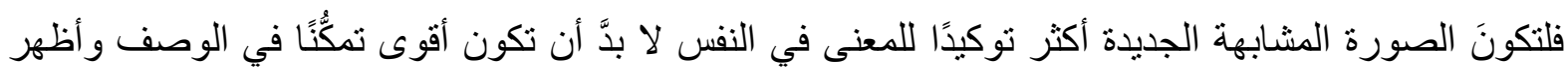
في الوجه المشترك، و "لا بدَّ أن يكون المشبّه به أعلى حالًا من المشبّه؛ لتحصل المبالغة هناك" '.وقيمة التشبيه لا تكتسب من طرفيه وحسب، ولا من وجه الثّبّه القائم بينهما بقدر استمدادها من الموقف التّعبيريّ" ؛ـ ليتجاوز

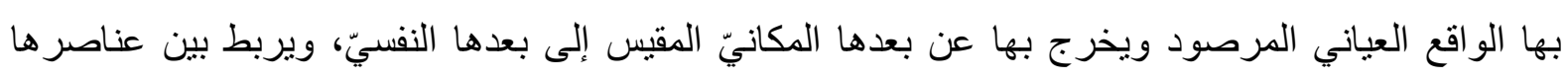

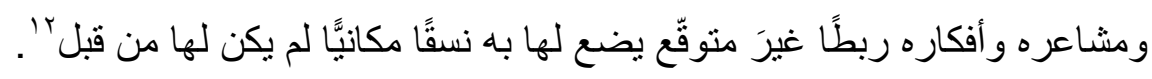

ويرتبط عنصر المفاجأة بالصور التشبيهيّة في أنهّا صور يأتي فيها طرَفَا التَّنبيه بشيءٍ جديد يحمل

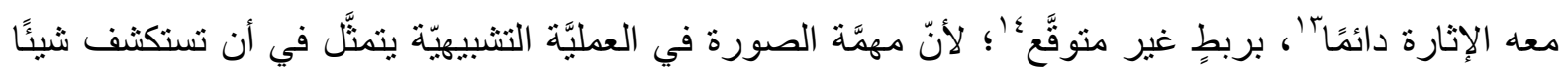

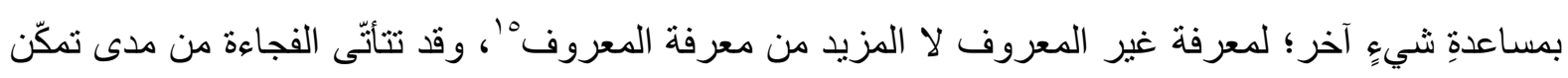
المبدع في رصد الأشياء والمواقف بما يلفت نظر المتلقي، حين يكتشف قدرة المبدع على التفكيك والتفتيت للعناصر المحيطة بالفكرة؛ ليقوم بتركيبها من جديد لدرجةٍ قد يجعل ما هو مألوف لدينا غيرَ مألوف، وما هو غير معتاد معتادًا "، فضلًا عمّا تتسبب به تلاك القدرة حين تصدم المتلقّي بحقيقة كون المألوف أصبح غير مألوف بفعل طريقة المنشئ و أسلوبه في الإبداع، حتّى أنّك تصبح بمقام من اعتاد على شيء ولم يكن كذلك لو لا

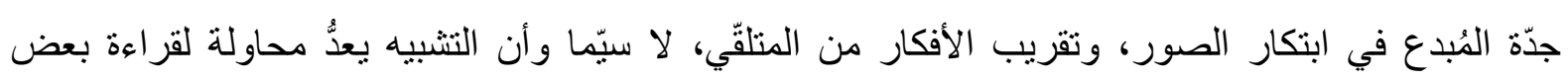

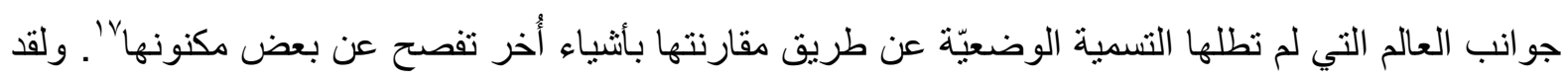
تو افر كلام أمير المؤمنين في نهج البلاغة على صورٍ جمعتْ بين ما هو مشاهد وبين ما هو محسوس؛ ليكون

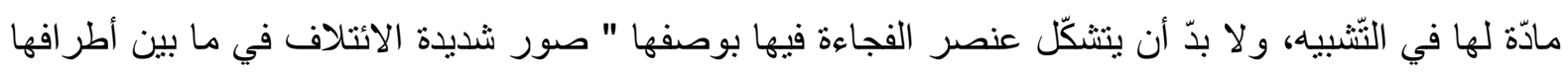
على الرغم من تباعد أجناسها بسبب ما أضيف، وركّب، و ألّف حتّى تو افقت في ما بينها؛ فإذا بها أنتجَتْ من ذلك

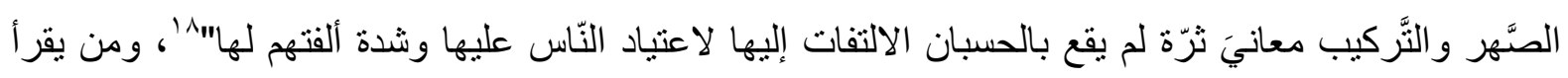

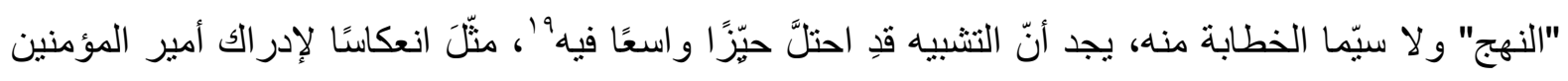

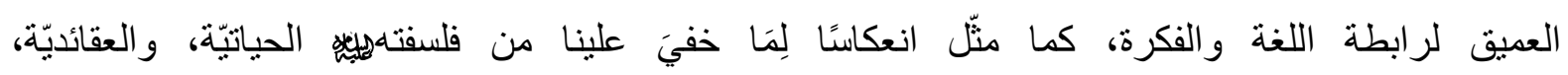
و السياسيّة...إلخ، ونظرته للإنسان والمجتمع، وعلاقتهما بالكلام عنده. وبدورنا سنعمل على انتقاء الصور التي 
تحمل عنصر المفاجأة على اعتبار أنّ علم الاسلوب قد وضع على عاتقه حصر الدراسة في أثرِ أدبيٍّ معطى لا

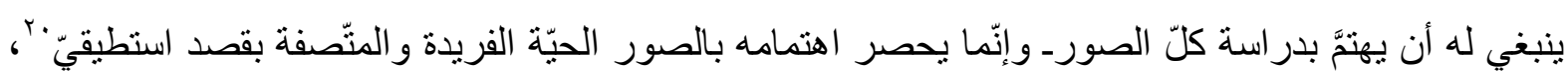
علمًا أنّ تلك الصور التشبيهيّة قد تنوّعت بحسب امتداد تجربة الإمامهليّه، وتعدّد تشبيهاته بأنواعها المختلفة، لذا سنستقصي النّادرَ، والفريد واللافت للنظر، و الجالب للدَّهشة منها في المدوّنة العلويّة التي انمازت بالصور المتنوّعة في موادّها وأنو اعها، تعرج بين شتى مناحي الحياة اليومية للإنسان في علاقته بالنبات، والحيوان، و الجماد، لذلك آلينا أن تتنوع شواهدنا للتحليل بين هذه المناحي التي نجد فيها مساحة للتحليل الأسلوبيّ لثواهد تتو افر فيها الفجاءة بشكلٍ أو بآخر، ومن هذه الثواهد قولهليِّة: "ألا وإن الخطايا خيل شُمْس حمل عليها أهلها، وخلعت لجمها، فتقحمت بهم في النار، ألا و إنّ التقوى مطايا ذُلل، حمل عليها أهلها، وأعطوا أزمّتنها، فأوردتهم الجنّة، حقّ وباطل، ولكلّ أهل، فلئن أمر الباطل لقديمًا فعل، ولئن قل الحقّ" "r. وهنا يبرز تشبيه مجمل حذفت

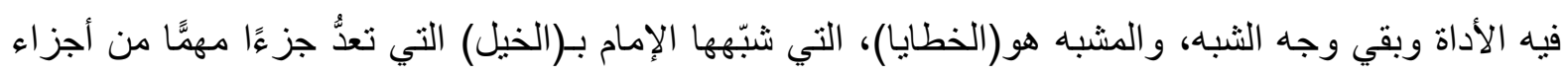
البيئة العربيّة، وفي هذه الصورة دواعٍ كثيرة لتوفّر الفُجاءة فيها يمكن أن نجملها بـ:

اـ قراءتهإبِّه: للمعقول المنمثّل في السلوك المخالف لثريعة الدين الإسلاميّ الذي سنّه الله للنّاس، وأسلوبه في تصوير ذلك المعقول بـ (محسوس) يعدُّ جزءًا من أجزاء البيئة العربيّة، ولكنّه ليس مجرّد تشبيه وحسب؛ بلّ إنّه

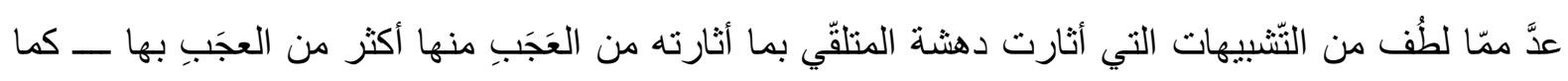
أثشار بذلك الثّريف الرضيّ ـ- وأنّها زيادة على ذلك فيها زوائد من الفصاحة لا يقوم بها لسان، و لا يطلع فجّها

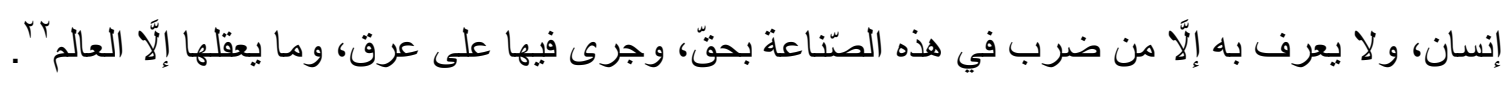
r- مارستْ هذه الصورة التشبيهية كسرًا في أفق نوقُع المتلقّي؛ فحين يشّبّه الإمائُ الخطايا بالخيل الثُمس هنا، يكون قد أعطى لتلك الخيل الجامحة هوية قائمة على النزق والطيش والخبط خبط عشواء، تصيب بأذاها كلَّ

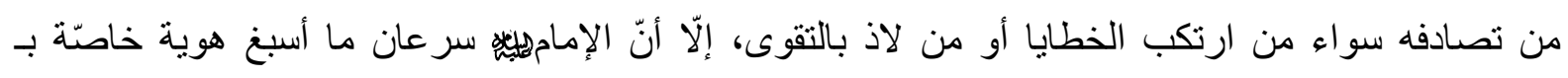

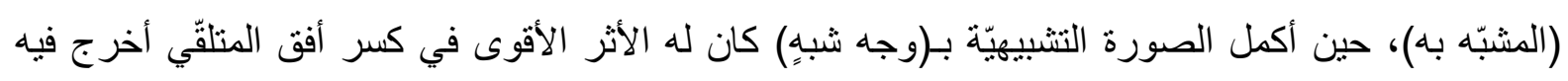
تللك الصورة المتخيّلة عن طيش وجموح تلك الخيل الجامحة عن حدود تصوُر اته التي تدور حول خبل شُمسِ تنطلق بلا لجم فتؤذي كلَّ ما يعترضها راسمًا صورة تللك الخطايا تصويرًا جديدًا؛ لتصبح الصورة المحتملة

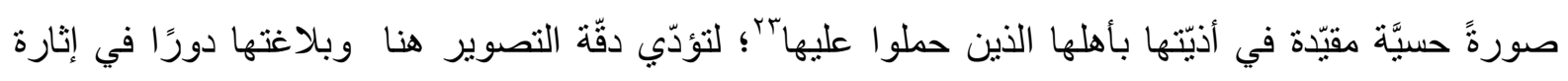
الرُّ عب في قلوب أصحاب الخطيئة ومقترفيها بهدف جعلهم يعيشون حالةً من التصوُر لما ستؤول بهم الحال فيما لو بقو اعلى إصر ار هم باقتر افها.

rـ كلّ تفاصيل هذه الصورة بما فيها من ألفاظ:(الخيل، الثمس، حمل، خلعت، لجمها، تقحّمت، بهم، النّار)

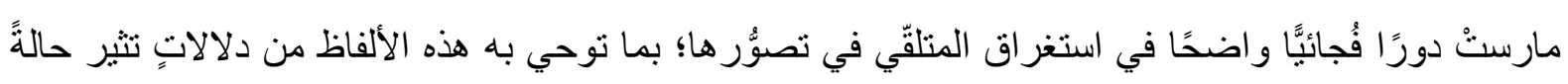

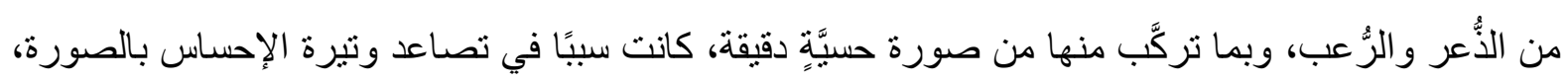

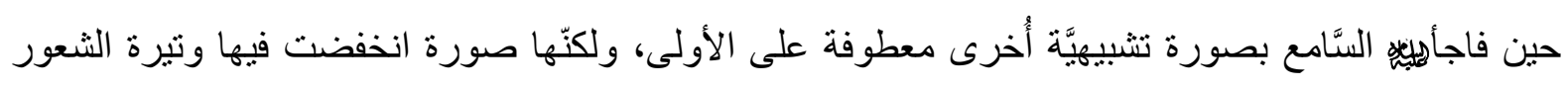

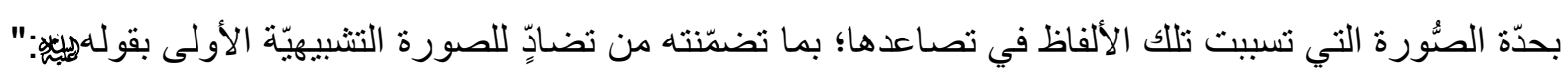

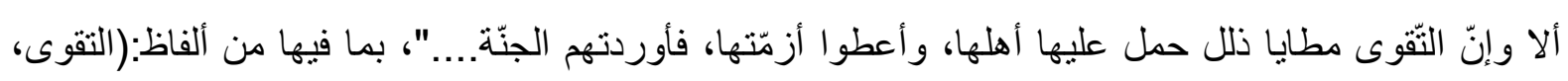


مطايا، ذلل، أعطو ا، أزمّتها، فأوردتهم، الجنّة) وما نتج عن ضمّها من تركيب جعل السّامع أمام منعطفٍ شندٍٍ في مفترق طريقين منضادّين تمامًا.

وفي صورة تثبيهيّة أُخرى لفتت انتباه الباحثة ما جاء في باب الحكم وقصار الكلم في نهج البلاغة

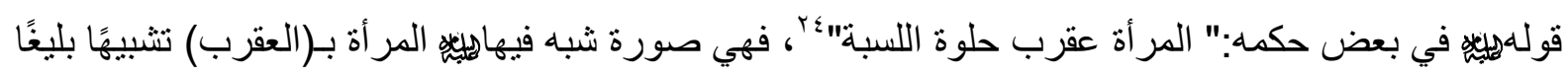
حُذف فيه أداة النتبيه ووجه الثبه، وأوّل ما يلفت النظر فيها أنّها صورة تثبيهيّة حصل فيها نوع من المقارنة بين طرفين حسيّين، ولكن ليس في صورة ما نظر إليه البلاغيون في وجوب أن تكون النّلة في التّشبيه نقلة

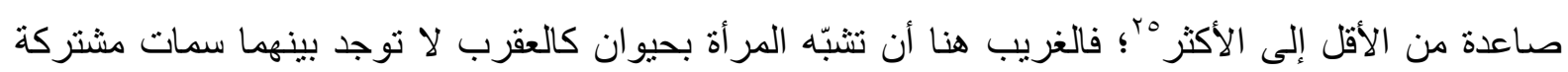

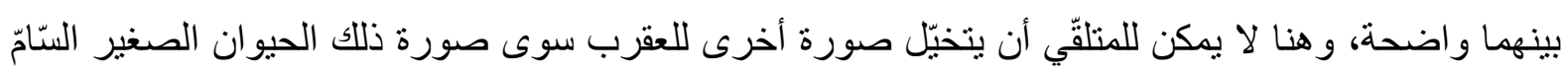
الذي قد يتسبّب في قتل الإنسان فيما لو تمكن سمُّها منه، كما أنها من الحيوانات التي تثير نفور الإنسان حتّى لو لو

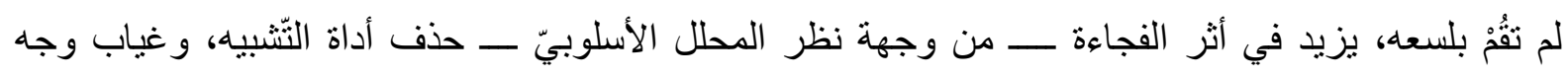
الثبه بين طرفي التّّبيه؛ لأنّ في ذللك إثشارة إلى تمكن صفات المشبّه به من صفات المشبّه حتّى كأنَّهما شيء واحدُ، وهنا يعيش المتلقيّ في حالة من الطلب والاشتياق إلى نيل معرفة العلاقة في البعد والقرب بين المشبّه

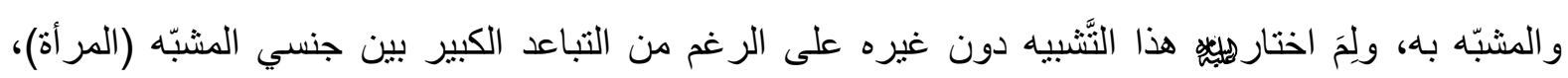
والمشبّه به (العقرب)، الذي جاء في صورة الخبر عن المرأة من الناحية التركيبيّة، لكن المتلقّي سرعان ما يفاجأ

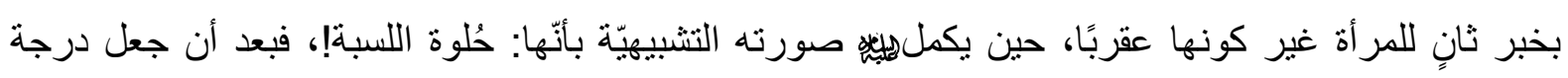


قام بإحداث كسر في أفق نوقّع المتلقي حين وصف لسعة تللك العقرب في كونها (حلوة اللسبة)، فكيف يمكن أن يجتمع متناقضان هما العقرب، والحلاوة!؛ لدلالة الأولى على العداوة و السُميَّة، ودلالة اللسبة على لعقة ولعة العسل). فنحن هنا بصدد صورة جمعتْ بين أشياء متباعدة، تخلّى فيها المُبدع عن الدلالة المعجيّة إلى لغة شعريّة تستفز و وعي القارئ من خلال إحداث خلل في أفق نوقّعه في نوع من ممارسة السلطة عليه، كما أنّ ما يميز هذه

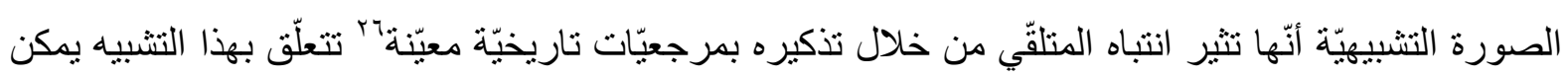
إجمالها بما نقل في الحديث بأنّ "النساء حبائل الثيطان"YYr، وبما قيل عن المرأة من قبل السَّلف بأنّ كيد النساء

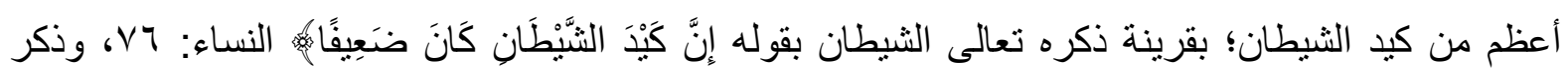

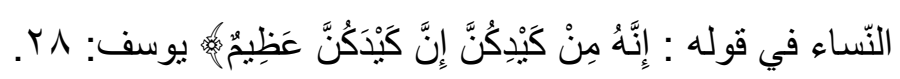

ومن وجهة نظر أسلوبيّة ترى الباحثة أنّنا يمكن أن نتصوّر الدَّهشة، والدُفاجأة الكامنة في هذه الصورة لأسباب تتعلق بأسلوباهلبيّة، وبأسباب تتعلّق بينية النصّ من الناحية الأسلوبيّة، بمعنى أنّا يمكن أن ننظر إلى هذه الصورة على أنّها تخلق عند المتلقّي ردّة فعل قد تحمله على الاضطلاع بعبهِ النصّ و النّّ اصئل معه بإيجابيّة

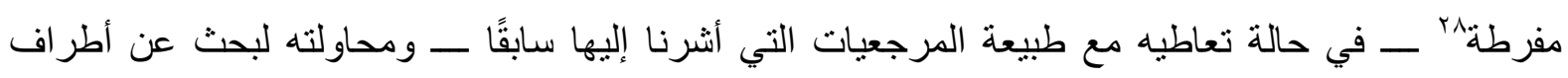
جديدة يمكن أن يعلّل بها سبب اندهاثـه بها؛ فيُقبل على النصّ بشكل آخر وجديد، كأن يقرأ الصورة التشبيهية بشكل معكوس ويتصور أن تشبيهابيّه للمر أة بالعقرب حلوة اللسبة، بأنّها صورة لتشبيه حلاوة المرأة، وأهميتّها

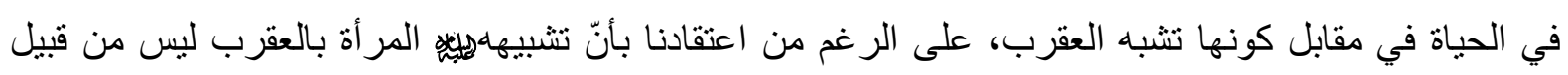


اعتبار المرأة عقربًا بكلّ ما يحمله جنس العقرب من سمات ليست بإيجابيّة، و إنما هو تثبيه اكتسب ندرته من

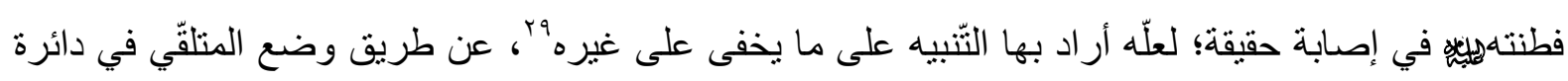

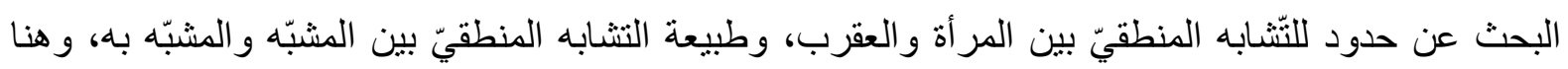

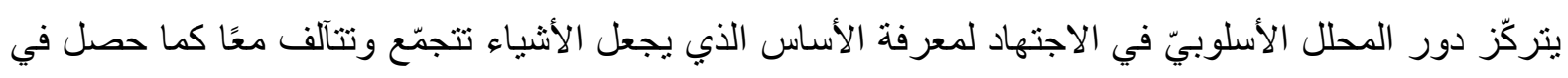

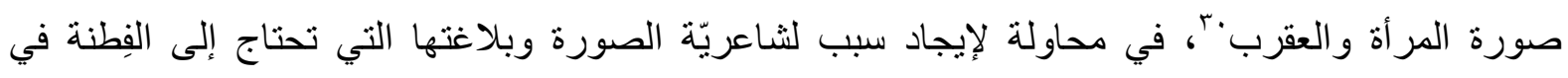
إدر اكها أيضًا، و إدر الك ذلك النَّابُهه بين طرفي التُّنبيه المتباعدين، وذلك عن طريق التأمّل كما يحدث في الفلسفة

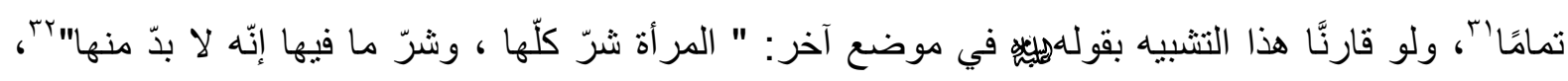
نستشعر أنّ وصف المراة في الموضعينِ ينطوي على ذمّ المر أة من جهةٍ، إلّّ أنّه ينطوي على تصريحِ بمدح لها يتمثّل في وصفها بأنها(حلوة اللسبة) في الصُّورة ذاتها من جهةٍ أخرى، ولا يمكن إغفال حقيقة أنّ الثريف الرضيّ لم ينقل لنا لمحة من ملامح السياق الذي شبه فيهليّه. المرأة بالعقرب على هذا النَّحو حتّى نفسّر في

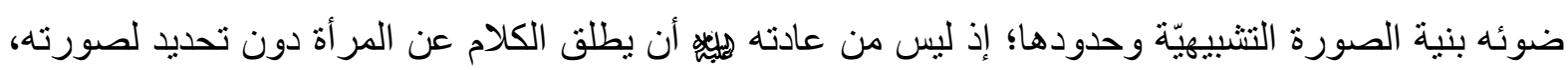

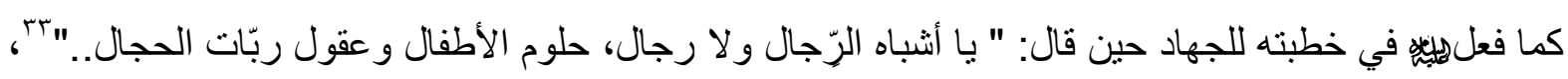

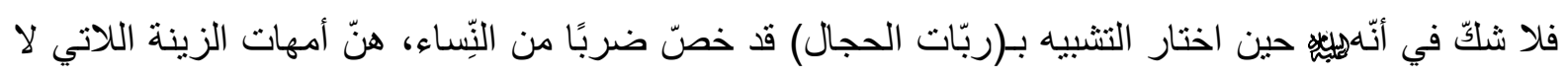
يبدين اهتمامًا إلّا لزينتهن؛ فيكون تفكير هن محصورًا في هذا الجانب، وبذللك لا بعني جميع النّساء وإلّا لما اختار هذا الوصف دون غيره؛ّ، لذلك يرجّح أنّ للصورة سياقًا كان الهدف فيه إيجاد مشابهة صادقة في عمقها بين طرفي الصُّورةهr ولكنّا نجهل طبيعة تلك المقاربة؛ لنجزم بقطعية وصف المرأة بالعقرب كما في طبيعة

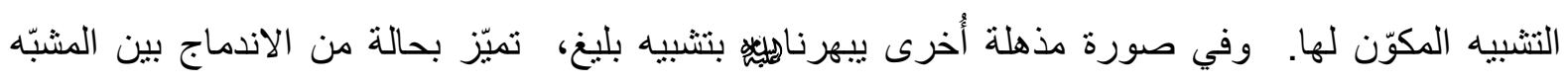

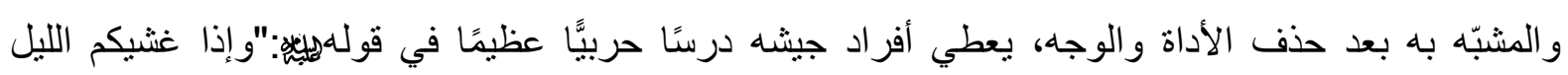

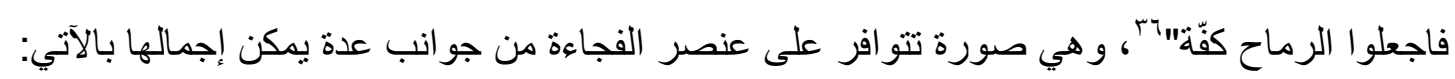
اـ قابليّة الصورة على استفزاز وعي المتلقّي، و إثارة تأمّله في مدى فاعليّة حذف أداة التّشبيه لجعل المثبّه

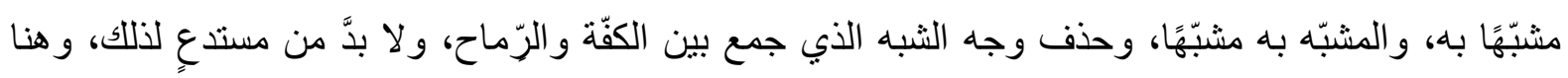

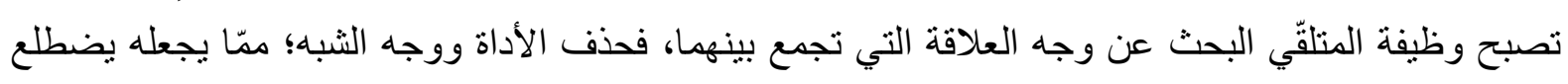
بمليء الفراغات التي يتركها النصّ ور اءهُ فيجعل المنلقِي في النتيجة يذهل بالنصّ، ويقبل عليه.

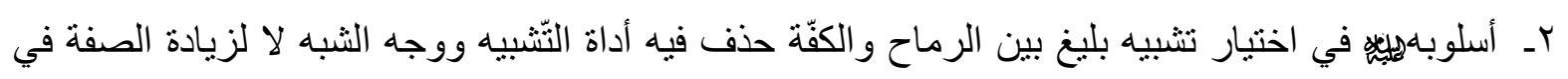
المثبّه به (الكفّة) - كما عبّر عنه البلاغيّون - بل لتنعانق صورة التّنبيه مع السياق العامّ الذي يولد علاقة

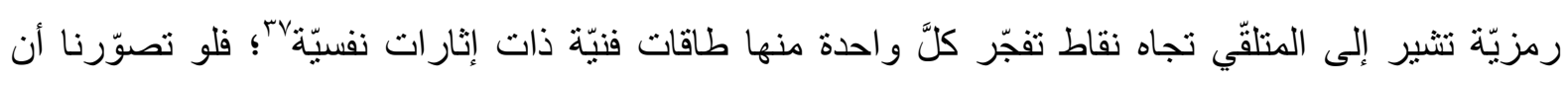
الإمامهليّة قال لأصحابه:(و إذا غشيكم الليل فاجعلوا الرماح كالكفة) أو نحو ذلك كان كمن لم يطلب التطابق في

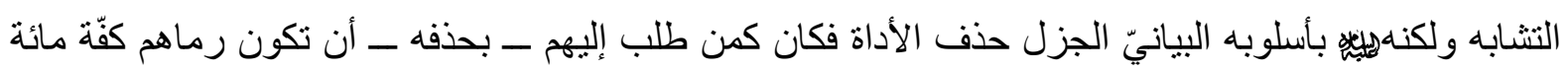

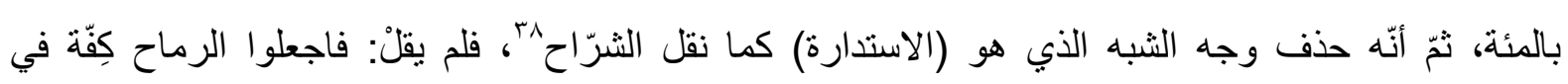

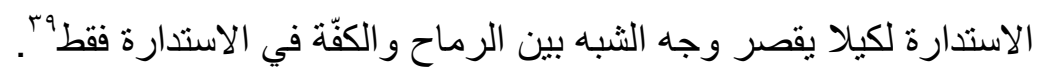


بـ تعدّد وجوه الثبه التي يمكن أن تتّسع لها هذه الصورة التشبيهيّة ممّا يضفي على الصورة سمة الاتّساع، وبذلك يمكن قراءة الصورة من وجوه عدّة، فقضلًا عن وجه الثبه بين الرماح والكفّة في (الاستدارة)، بإمكان

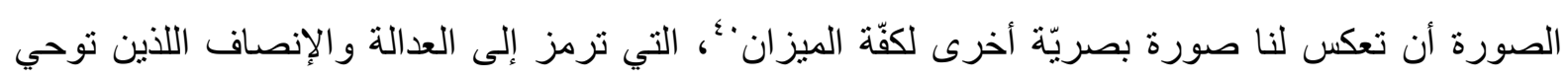
بهما اللفظة، وفي وجه ثالث يمكن أن يقرأ وجه الثبه في قولهإِيّة: "فاجعلوا الرماح كفّة" على أنّه انعكاس لصورة كلّ جنديّ يجعل سلاحه قريبًا منه، و على هيأة تجعله وكأنّه كفّه التي في ذر اعه؛ ليتمكن من استعماله

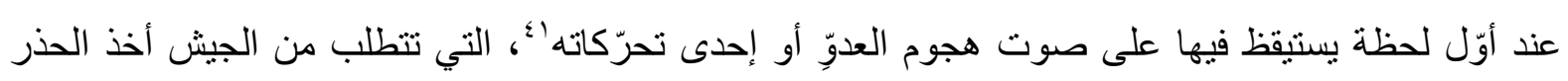

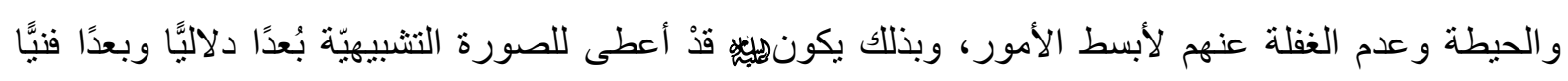
انعكس على المشبه به بشكل يجعله قادرًا على إنتاج تداعيات للصورة بكامل أحداثها ووقائعها إلى عين الناظر بمشهد ألفته جوانب الحياة، "فتر اها صُورًا شديدة الائتلاف في ما بين أطر افها على الرغم من تباعد أجناسها؛ بسبب ما أضيف وركّب و ألّف حتّى نوافقت فيما بينها فإذا بها معانٍ ثرّة لم يقع بالحسبان التلفّت إليها لاعتياد الناس عليها وشدّة ألفتهم لها" 'كأ. ويأتي التشبيه العلوي في مدوّنة النهج بدور ليس المقصود منه إعطاء مجرد

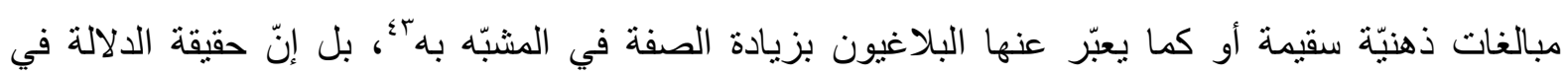

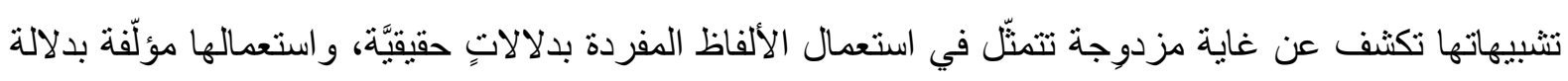
أُخرى في تشكيل صورها، وأغلب صور الإمام التشبيهيّة على الرَّ غم من أنَّ أغلبها مبنيَّة على عناصر حسيّة

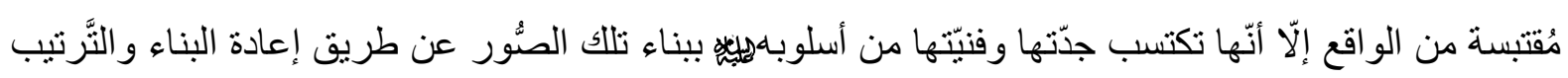

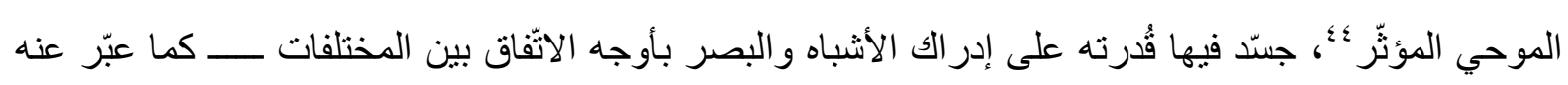
بذلك أرسطو ه؛ - لا بقصد التشبيه بحدّ ذاته، و إنّما لإيصال الفكرة بأكثر الطرق اختصدارًا، وكثافةً، وتأثنيرًا في الوقت نفسه، كما نجد في قولهإيلّة: "فما راعني إلّا والناس حولي كعرف الضبع إليّ، ينثالون عليّ من كلّ جانبٍ حتّى لقد وطيء الحسنان وشتّ عطافي، مجتمعين حولي كربيضة الغنم، فلما نهضت بالأمر نكثت طائفة،

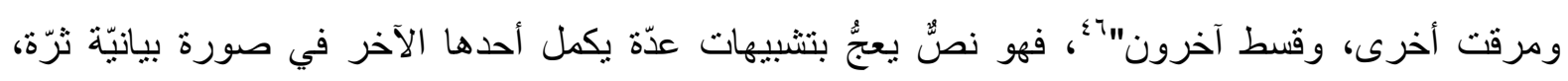
و اللافت في هذه التشبيهات أنّها تقدِم قر اءة عميقة لسياق الموقف الذي قيلت فيه بشكل يعكس أصالتها في النَّبير

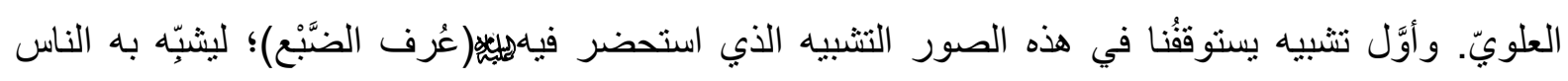
الذين أقبلو العليه لأجل المبايعة؛ لينقل لنا صورة تهافتهم عليه في كثافة عرف الضبع الذي يضرب به به المثل في

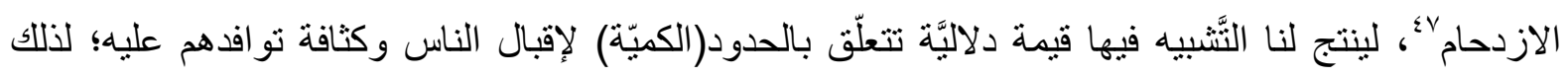
تبقى الصورة التشبيهيّة في حدود تللك الدلالة فتر اها تنفتح دلاليَّا على ما بعقبها من تر اكيب، ما يجعلها تسترسل

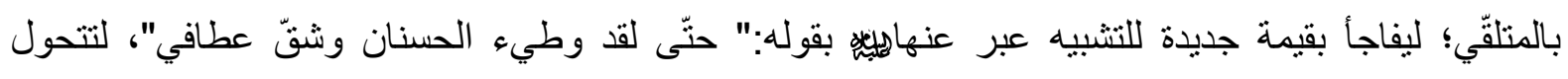
صورة التشبيه في قوله:هليّه: : "فما راعني إلّا والنَّاس حولي كعرف الضبع ينثالون حولي من كلّ جانب حتّى لقد

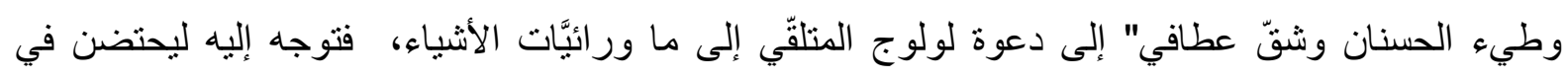
مقاطف مختلفة تلك الإيحاءات التي تظلّ تحوم فوق الصورة التشبيهيَّة ليحاول اقتناص ما أمكنه من طيورها المختلفة والتي سيظل بعضها يرفت بأجنحته حو اليه، و لا بستطيع أن يقبض عليه"دء، فتشبيه قيام الناس وكثافة تو افدهم للبيعة يبقى حبيس الأفق التي حدّدها مجرّد تشبيههم بذلك، حتّى اكتملتِ الصورة بإخباره عن حالة

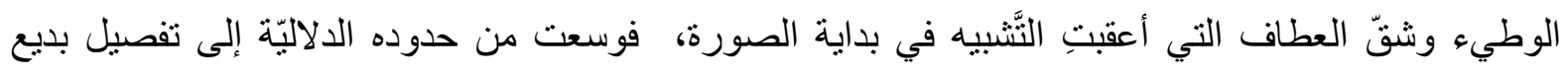


لصورة تللك المبايعة وتفاصيلها الدقيقة، وما يزيد في تلك الدقة أنهيبه استعمل التشبيه مرّة أخرى في الصورة نفسها بوصفه لهم :" مجتمعين حولي كربيضة الغنم"، وهنا قد يقف المتلقيّ حائرًا أمام التعبير الذي تخللته فجوة،

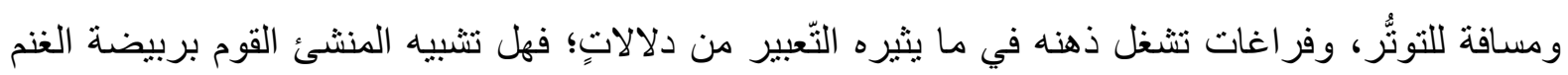

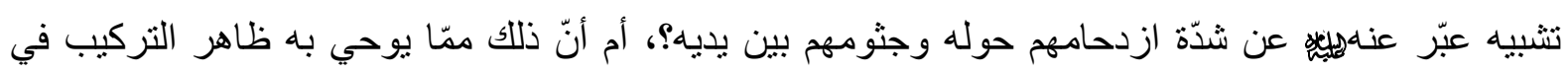

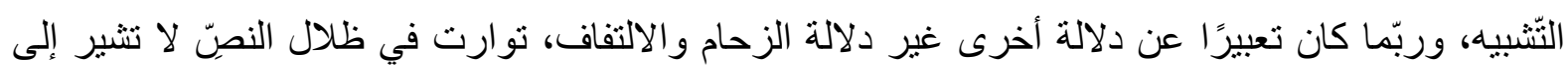

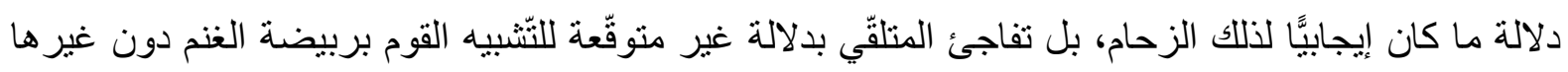
من الصور المتعلّقة بتشبيه القوم في نهج البلاغة؛ إثـارة إلى قلّة فِطنتهم، وبُعد تأمّلهم في عمليّة المبايعة تلكا!

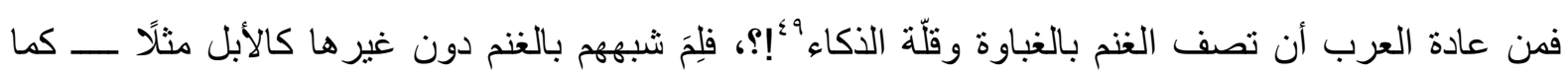
اطدّرد في تثبيهاتهابيّهُ، وهنا يمكن تفسير عمليتي الوطيء، والثقّ التي عبّر بها الإمام في الصورة، على أنّها

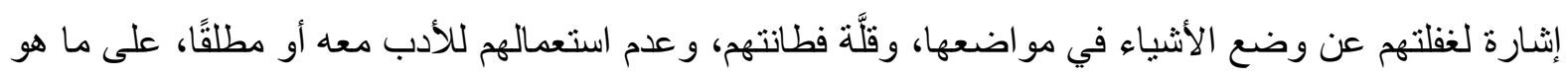

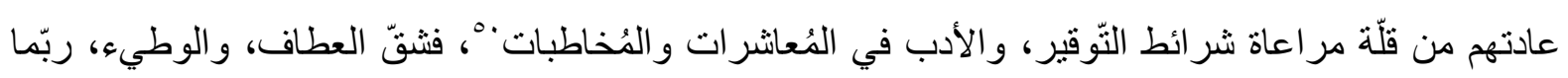
يكون إشارة إلى عدم استعمالهم الأدب في طريقة مبايعتهم المزعومة، وهو وجه الثباه بينهم وبين ربيضة الغنم، التي لا تفقه من شر ائط ذلك شينًا!، وبهذه القرائن اللافتة يمكن أن نصل إلى نتيجة تعبّر عن سليّيّة موقفهم الذي وهي

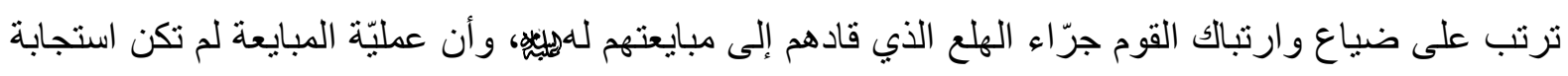
لنداء العقل بقدر ما كانت ردّة فعل على ما جرى من أحداث تتعلق بظروف مقتل عثمان، واستجابة لنداء يتعلق

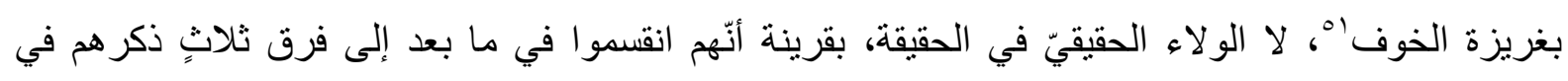

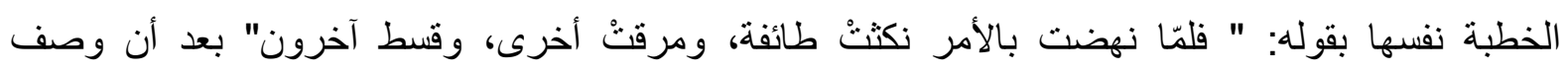
اجنماعهم للمبايعة ذاك، وبذلك تتوافر الصورة التشبيهيّة على مفاجأة المتلقيّ بمعطياتٍ قد تغيب عن ذهنه عند

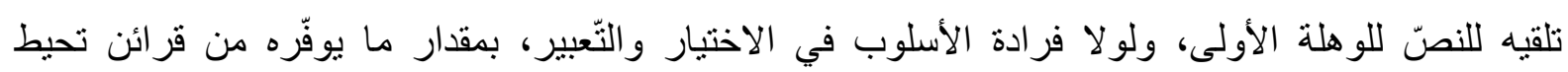
بالصورة لما أمكن الالتفات لها مطلقًا.

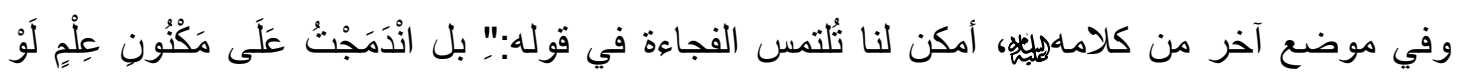

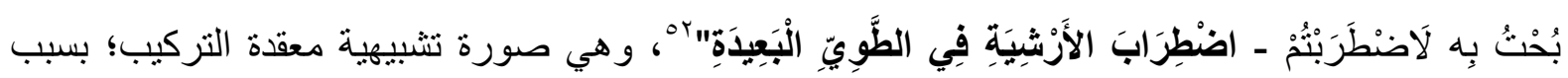
تعدد مفاصل التشبيه وتعلقه بأكثر من لفظة، فضلً عن بعد(وجه الثبه) بين اضطر اب القوم وبين اضطر اب

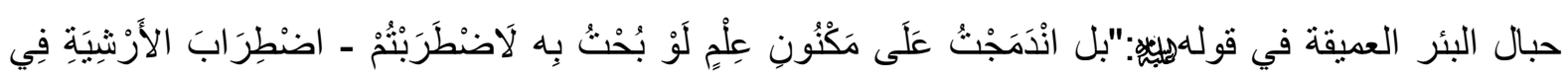

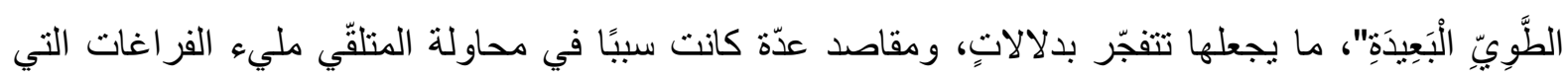

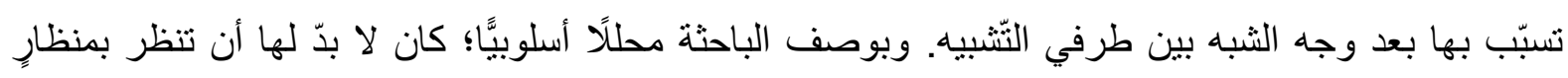
أسلوبيّ لما يحقّة تركيب الصنّورة من عنصر الدَّهشة، واللذّة الناتجة عن استشفاف العلاقة بين المشبّهه و المشبّه به، ووجه الشبه، و العلاقة الحقيقيّة بين اضطر اب حبال البئر، وحال القوم لو أخبرهم بما انطوتُ عليه مكنونات علمه؛ لذا أمكن لها أن تتبع مسبباتٍ تلك الدهشة و اللذة في هذه الصورة بالآتي: 1 ـ توافر الصورة على استعاراتٍ، وكناياتٍ، وتثبيهاتٍ خطيرة اندمج عليها كلامه في هذه الخطبة التي

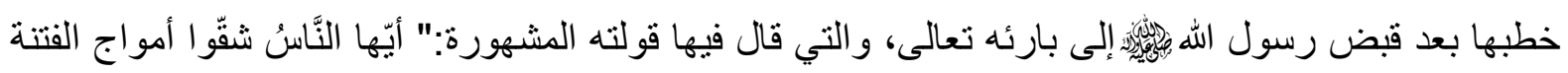




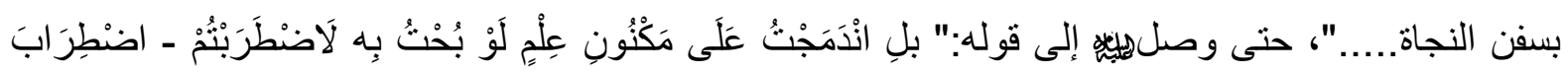

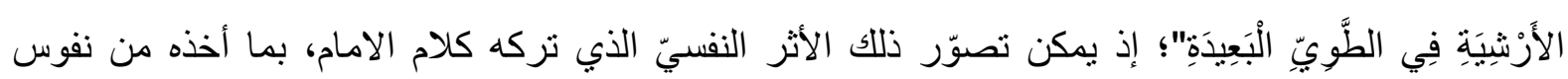

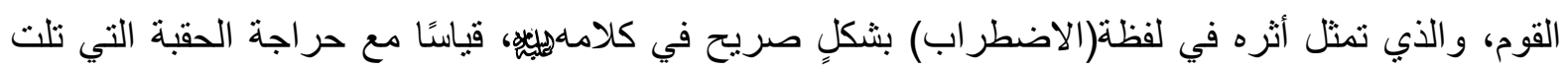

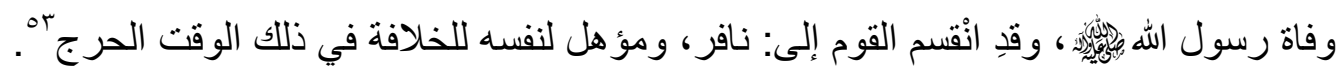

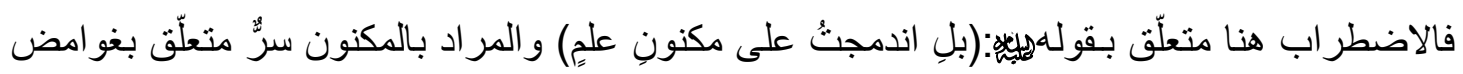
مسائل القضاء والقدر \&ْ، وهو من الأمور التي تثير قلق متلقّي الخطاب وتزيد في اضطرابه، فضلًا عن تلك الفُجاءة التي يثير ها خطاب الإمام بإثنارته الى ما حدث يوم الغدير من عهد رسول الله إليه وكان القوم جميعًا على علم بما دار وقيل فيها ولو باح الإمام بما علمه من عاقبة هذا الأمر لم يكن لهم ذلك النظام الحاصل في ذلك هلك الوقت ليأس بعضهم من وصول الأمر إليه وخوف بعضهم من غلظة بعضهم على بعض... هـ فيما يخص شأن

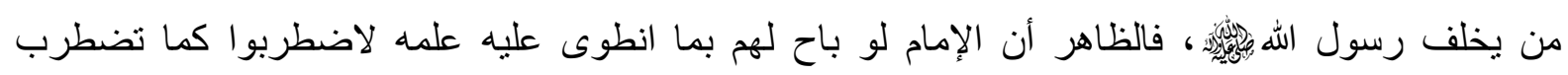

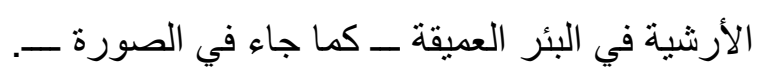

ז- بعد وجه الثبه في الصورة التشبيهيّة؛ ممّا يسبب إمكان احتمال الصور في داخل النظامّ؛ فالإمام حين اختار هذه الصورة من التشبيه يفترض أن يكون في مقصده وجهُ للشبه بين(اضطر اب الحبال في البئر العميقة)، وبين(اضطر اب سامعي علمه)، ولكنّه محذوف لا يمكن القطع به بسبب تعقيد الصورة وتفجّر ها بالدلالة، فوجها

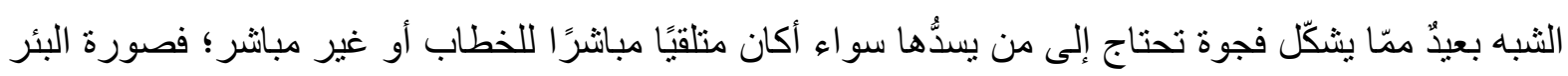

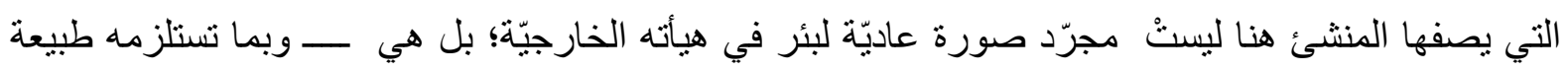

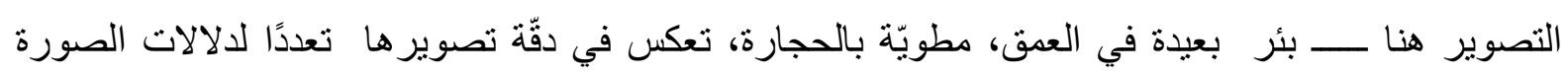

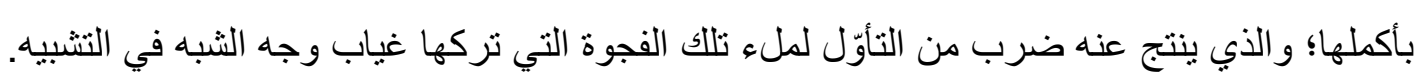

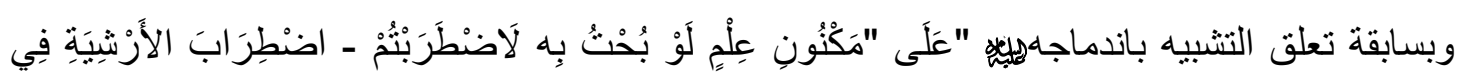

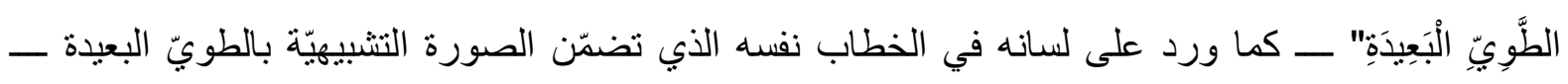

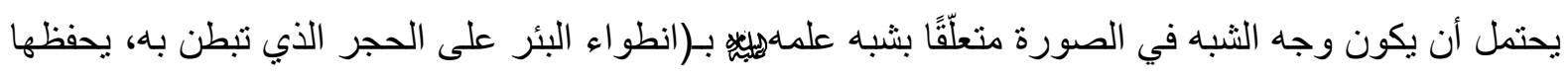

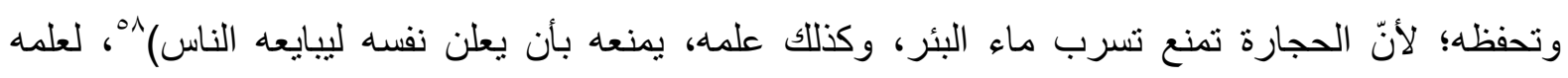

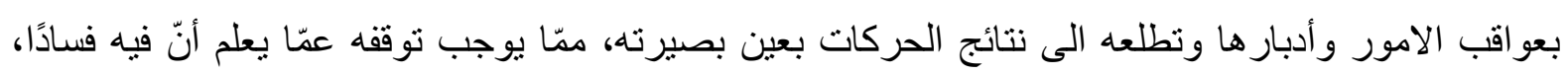

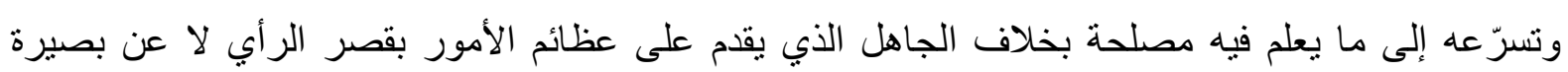
قادته إلى ذلكو 9.

وربّما يكونهيلِّ قد شبّه علمه العميق بعمق البئر، وشبّه اهتزاز الحبال داخل هذه الآبار باضطر اب من

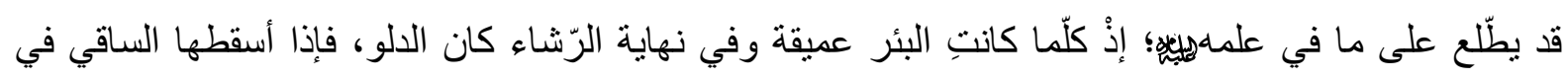
البئر، احدثت اهنزازًا؛ لطول الرشاء الذي سبّبه عمق البئر واضطربتِ الحبال، وبدت قلقة، غير مستقرّة، فكذلك

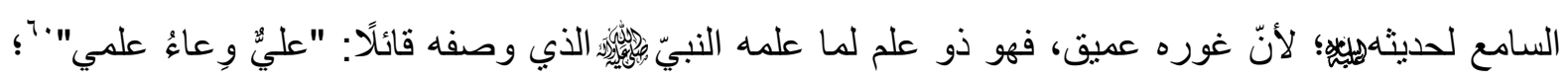
لذلك فالوصول إلى حقّ علمه أمر صعب، من طلبه اضطرب، وقلق لما يسمعه منه، ولحصل معه في الاضطر اب كالذي يحدث مع الرشاء”"، و هذا ما يتساوق ووقع الفجاءة التي يتعرّض لها متلقّي الخطاب في ما 
لو أدركوا أن الذي منعهلهيّه عن المنافسة في هذا الأمر، والقتال عليه؛ شغله بما انطوى عليه من العلم بأحوال

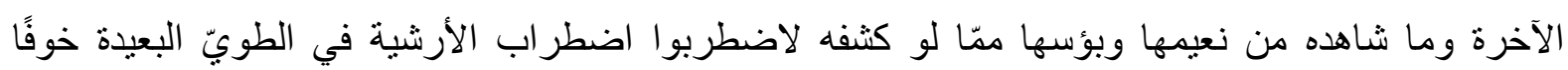

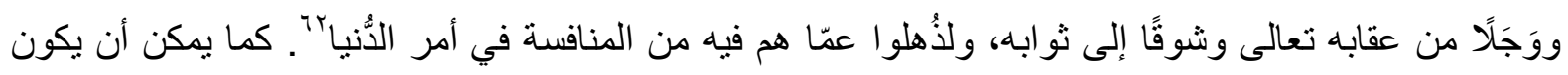

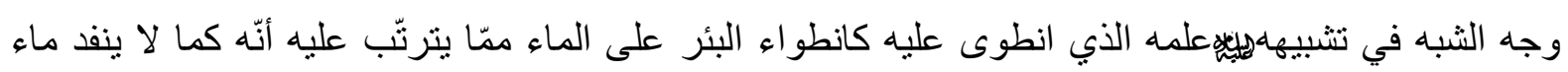

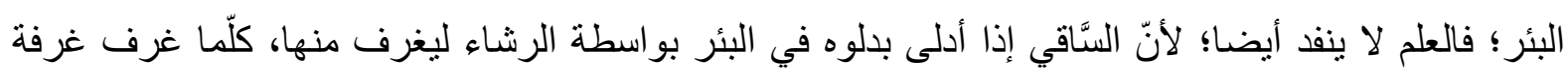

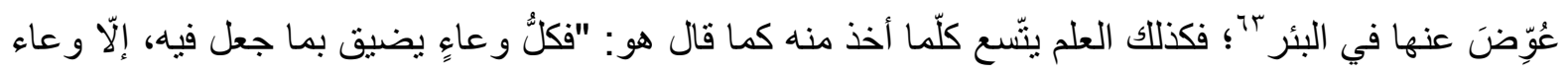

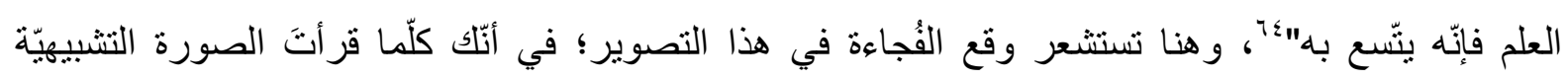

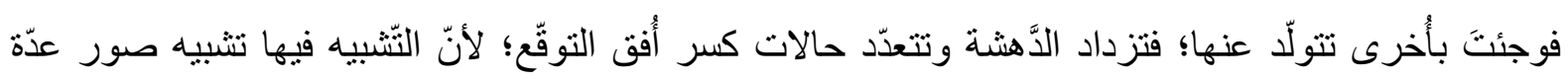

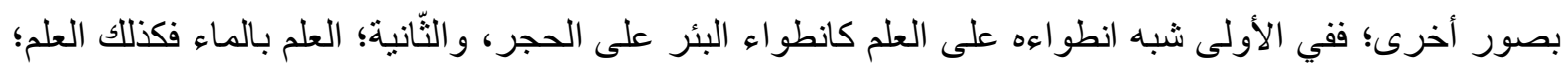

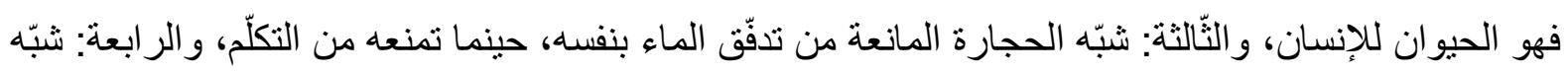

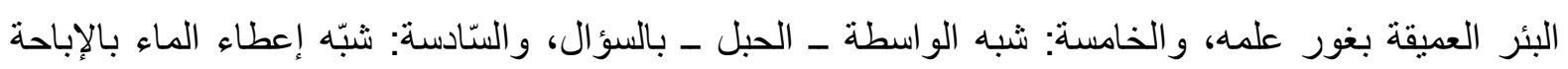

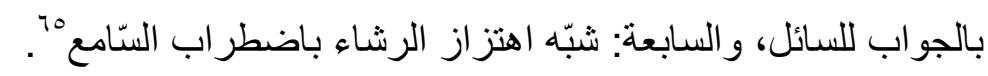

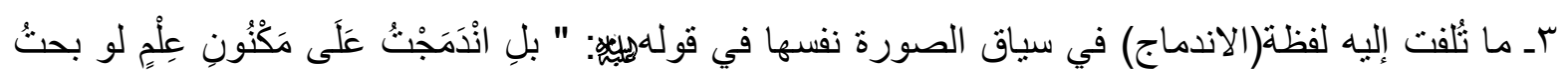

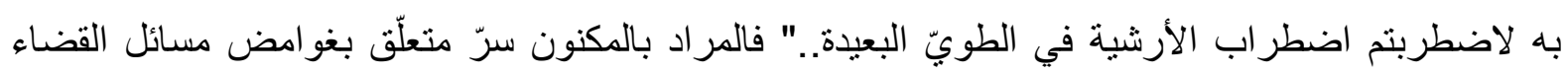

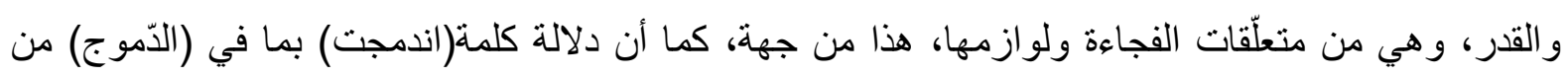

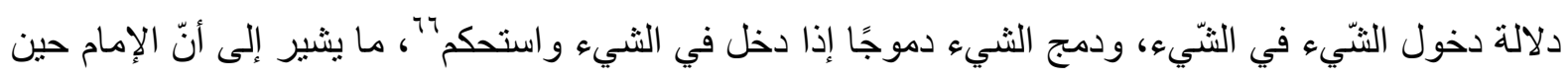

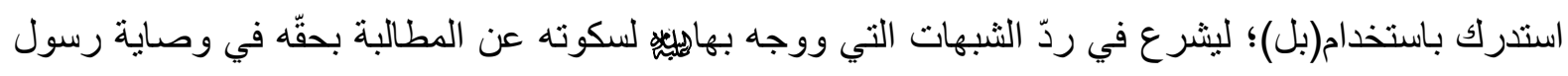

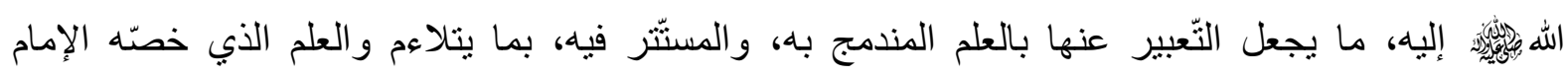

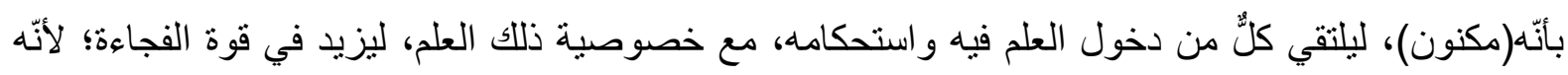

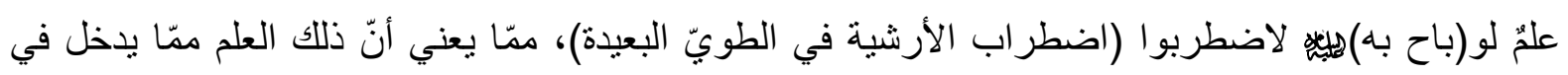

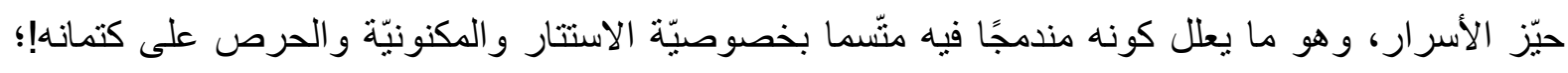

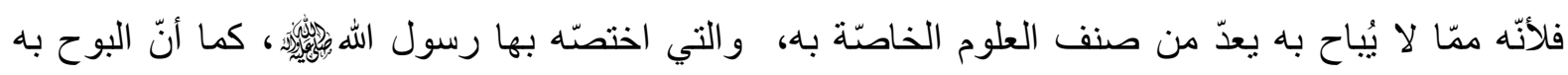

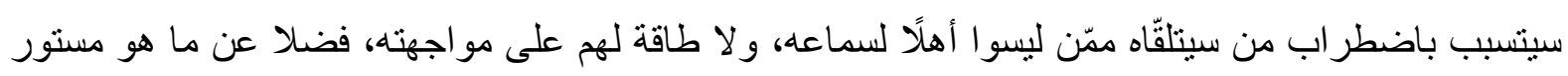

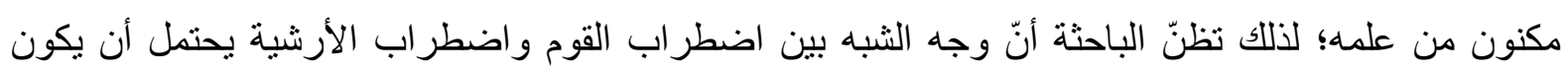

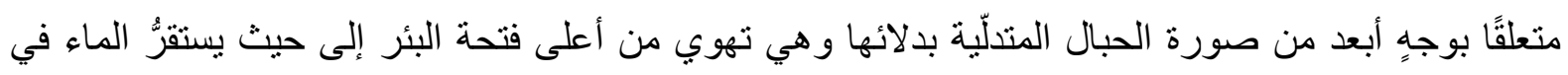

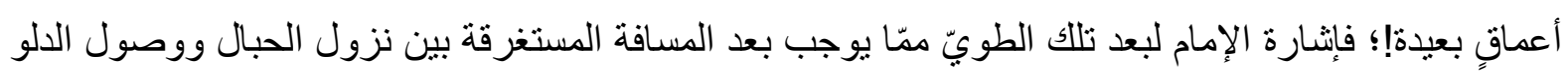

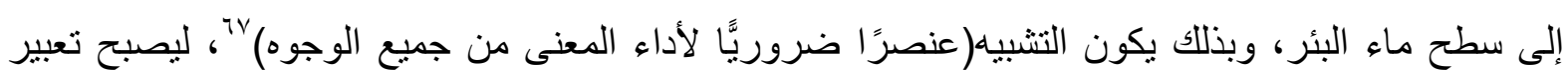

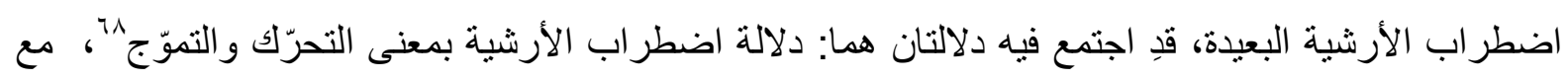

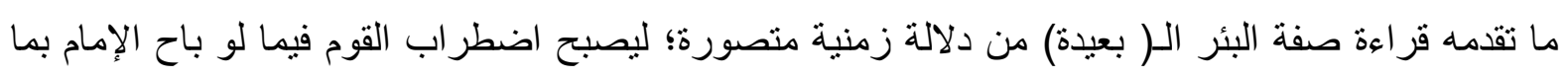

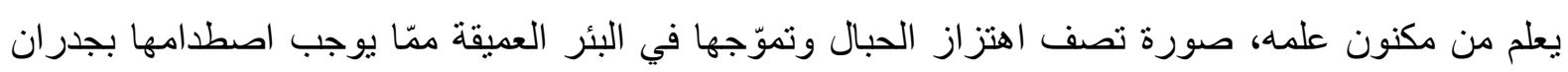

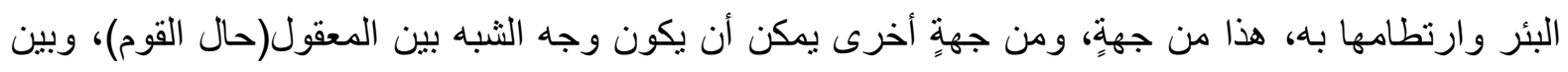

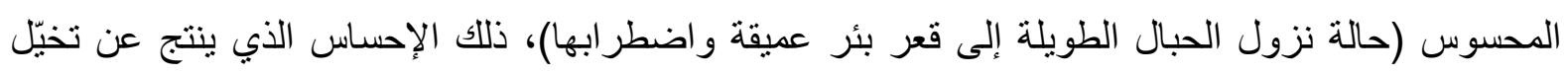




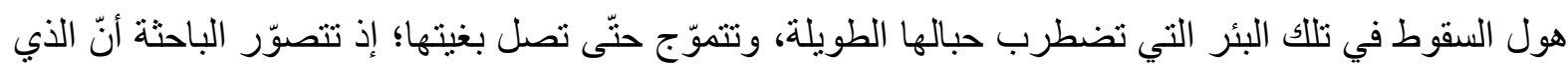

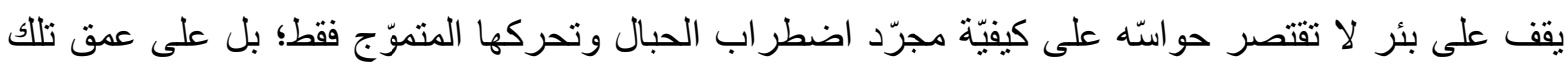

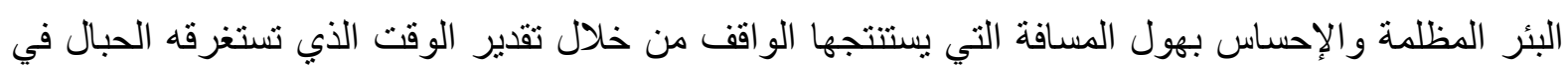

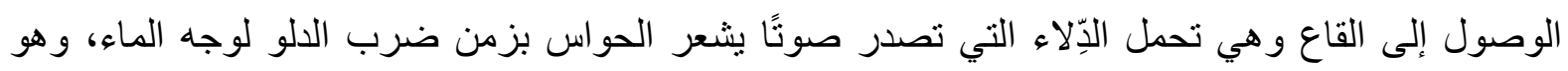

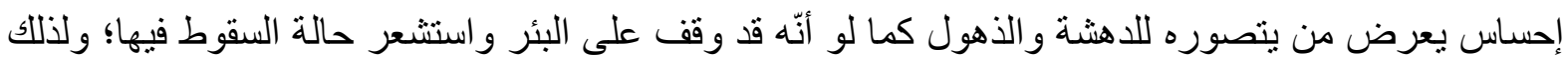

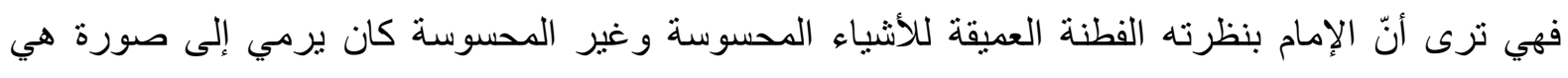

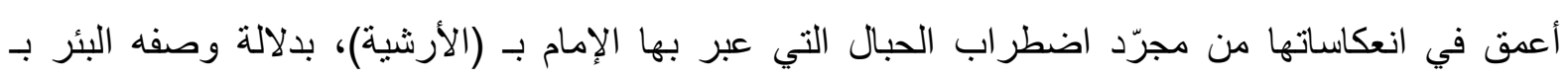

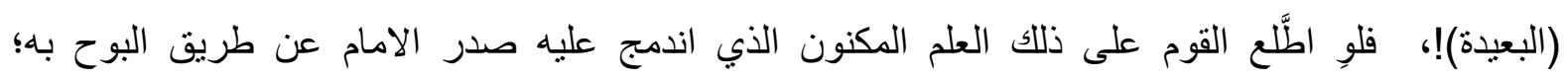

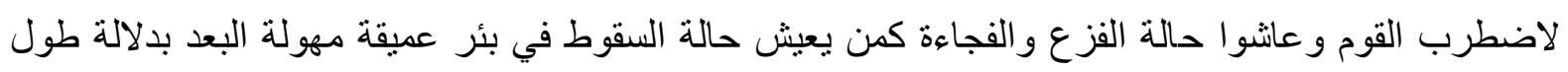

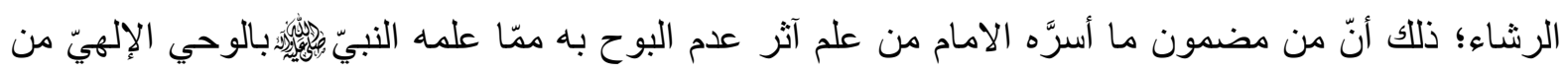

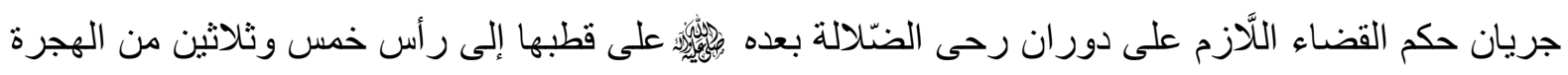

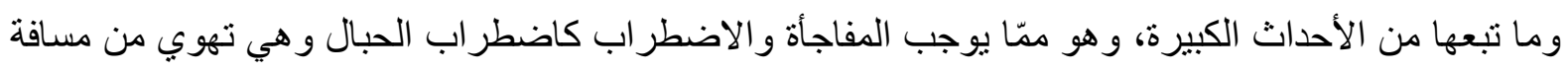

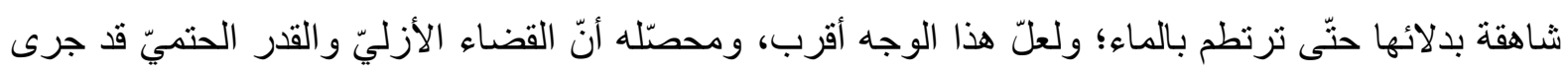

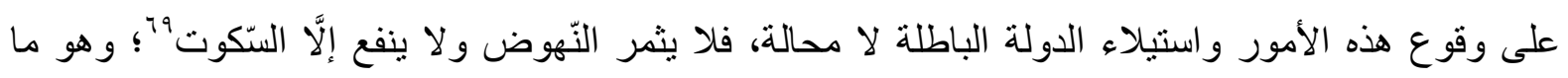

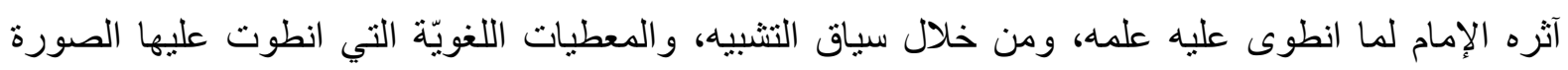

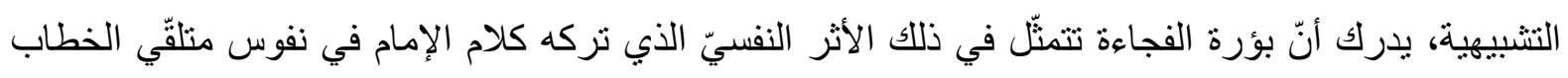

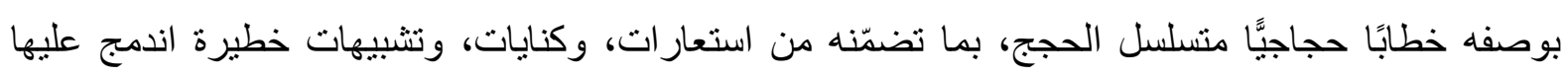

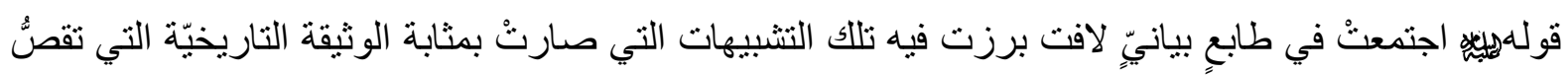

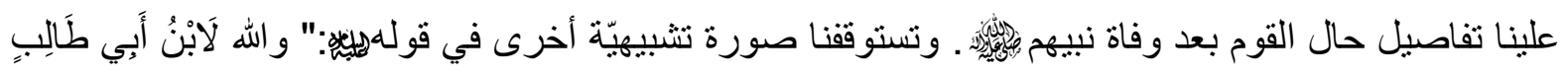

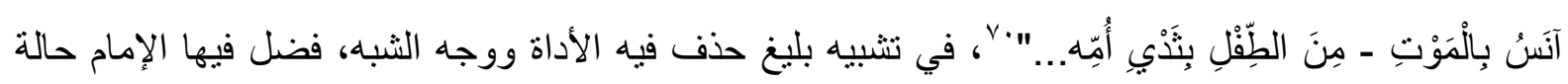

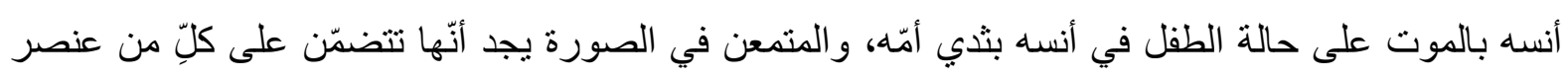

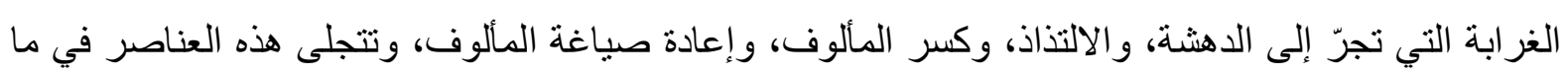
الآتي:

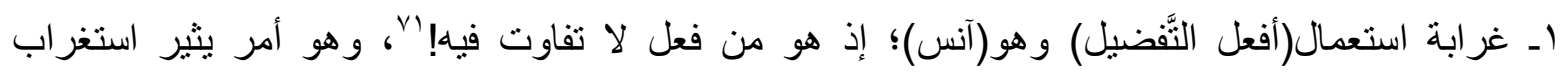

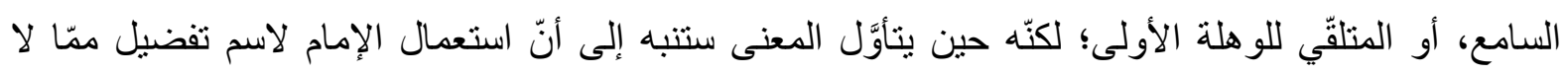

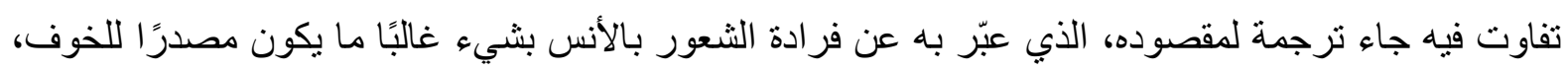

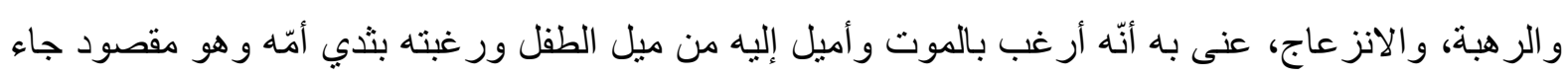

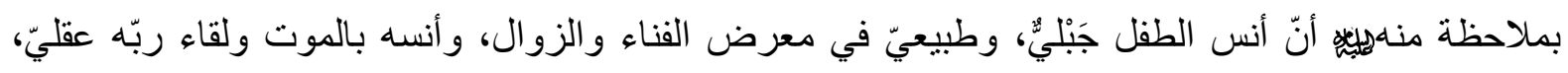

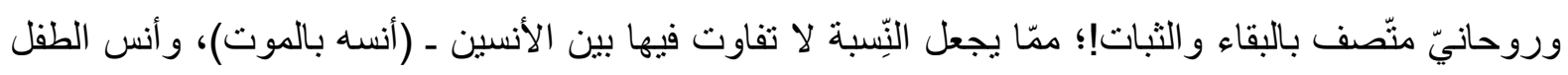

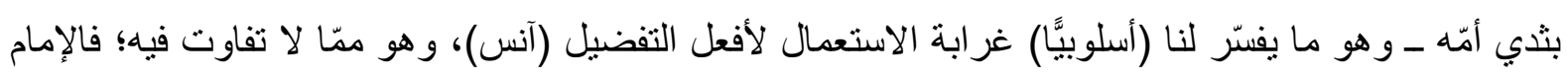

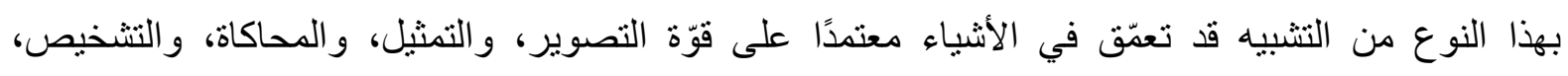

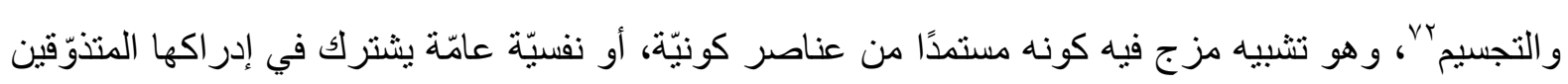


كافّة، كالرضاعة، وأنس الرضيع بها؛ فهي ممّا هو شركة بين الناس والأمم، إلّا أنّ بعضًا ممّا هو مشترك بين

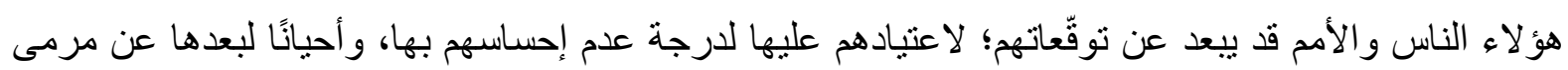
حو استّه، وبذلك يكون تصوير هاو إعادة الإحساس بها؛ ممّا يجعلها أحفظ لبقائها، وحيويتّها، وتأثثير ها في الأجيال

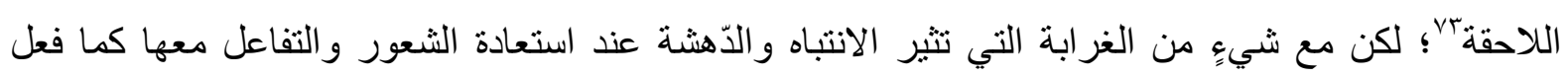
الإمام في إعادة تصوّر حالة الأنس بثدي الأمّا! من جهة، ومحاولة تفسير وجودها في الكلام من جهةٍ أخرى!،

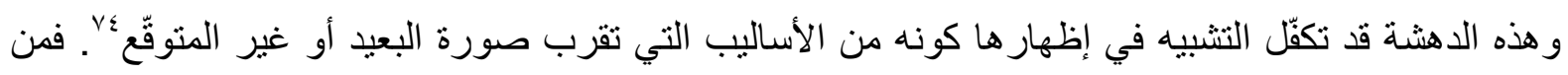

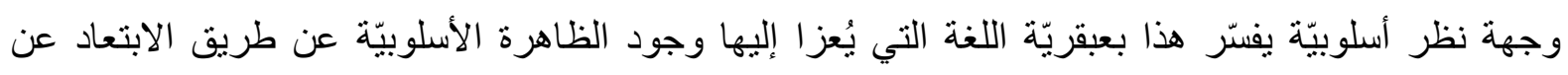

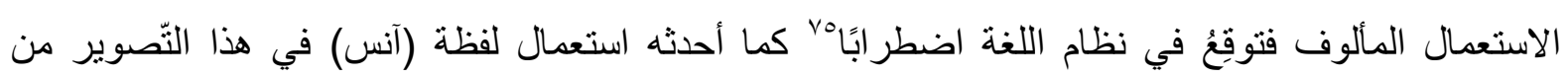
الناحية الصرفيّة الصيغيّة، ومن الناحية النفسيّة الثعوريّة، ومن الناحية الدلاليّة، فمن عادة التشبيه البليغ أن يحذف فيه الأداة ووجه الثبه، لكن هذا التتبيه تجاوز ذلك إلى حذف المشبّه به وهو (حالة استئناس الطفل بثدي أمّه) لتصبح الصورة أقوى وآكد وأبلغ، فورود نتبيه بليغ حذف منه الأداة حتّى كأنّ طرفيه (ابن ابي طالب)

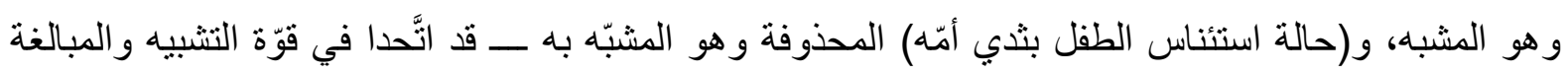
في المفاضلة بين الطرفين باستعمال لأفعل التفضيل بما لم يألْهُ المتلقّي؛ إذ كان المتوقّع أن يكون التشبيه على ولى

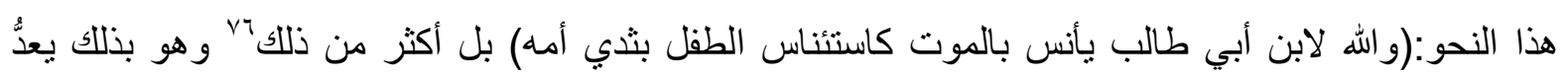
كسرًا لأفق التوقّع لدى المتتبع لصورة التشبيه؛ لاجتماع هذه المعطيات فيها.

r- تو افر هذا التشبيه على معانٍ متجددة بتعدّد القراءات ممّا يضع كلام أمير المؤمنين في منزلة الإعجاز الذي

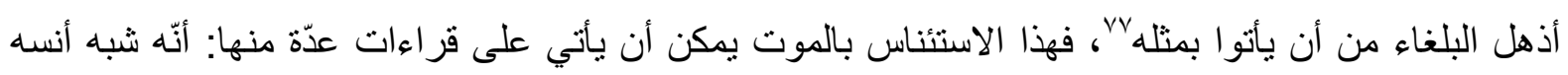

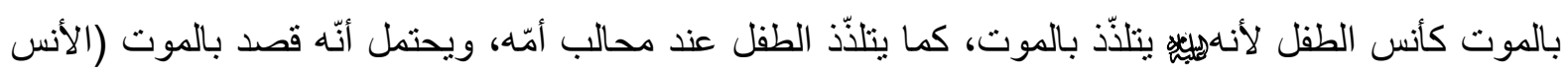
نفسه)؛ كونه لا يخاف الموت بل يجعله أنيسًا له في وحدته، كما يكون أنبس الطفل ثدي أمّه، و لا بيتبعد أن

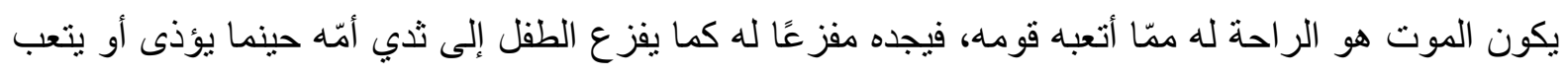

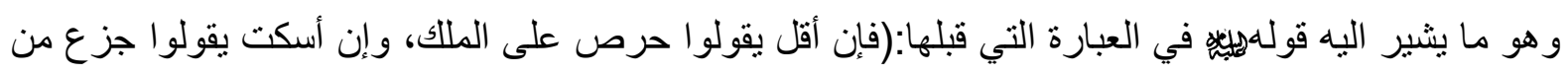
الموت، هيهات بعد اللتيا و اللتي! و الله لابن ابي طالب آنس بالموت من....) ممّا يوحي بجزعه منهم وتعبه منهم،

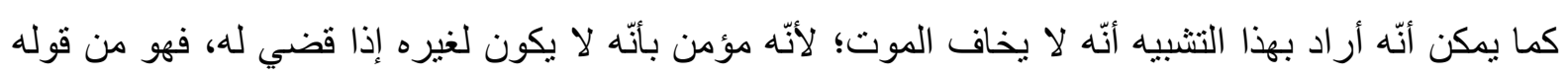

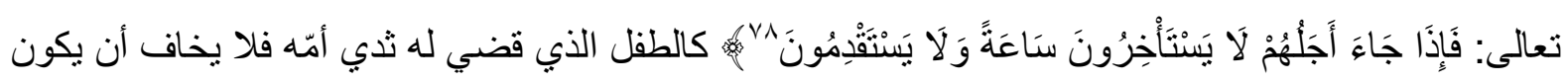

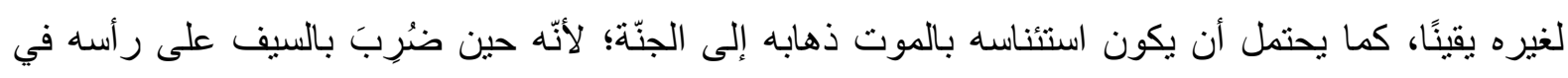
حادثة استتهاده قد صر خ بقوله: " فزت وربّ الكعبة" ، و الجنة تتناسب في عطائها مع عطاء الثدي، لبنُه للطفل

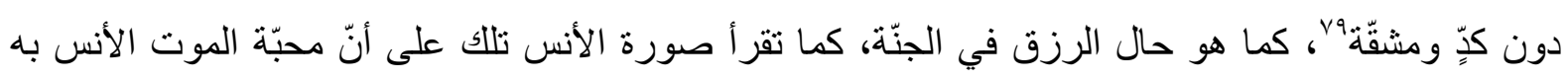
منمكن في نفوس أولياء الله؛ لكونه وسيلةً لهم إلى لقاء أعظم محبوب و الوصول إلى أكمل مطلوب.، هونة وهو أمر

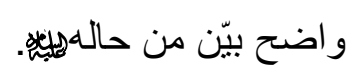

rــ عدول الإمامدليّهُ من مساق إلى آخر في الكلام؛ فعدل بالمشبّه من مقام التكلم في قوله" فإن أقل يقولوا حرص على الملك، وإن أسكت يقولوا: جزع من الموت"، إلى مقام الغيبة في قوله:" لَابنُ ابي طالب آنس 
بالموت من الطفل بثدي أمّه" مستعملً أسلوب الالتفات ليفاجأ المتلقّي بالتكنية عن اسمه بعد أن كان بتكلم بصفة



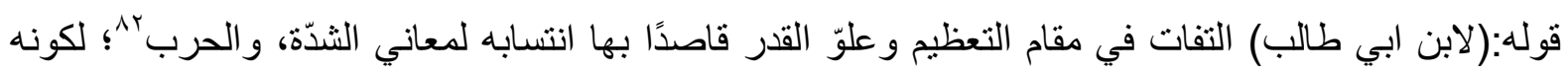

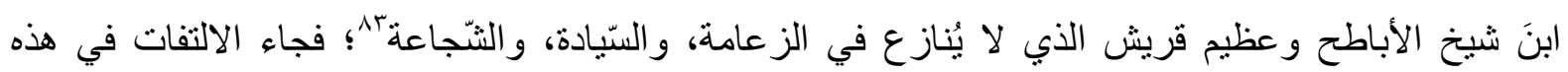

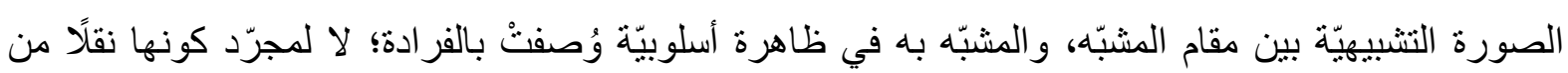
أسلوب الى آخر تطريةً للسَّامع، وتجديدًا لنشاطهءُ؛ بل لأنّها في علم الأساليب تعدُّ كسرًا في البناء، وخروجًا

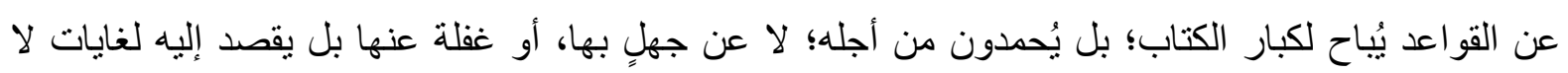
حصر لهاه^، وهو. ما اقتضاه السياق، واستوجبه المعنى זی؛ فمن يراجع ظروف الخطبة المقامية، ويستقري

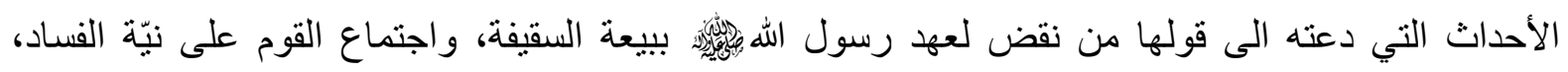
وتخريب عصبة الدّيّن؛ يجد أنَّ الالتفات ممّا اقتضاه السياق للتنبيه على عِظَّم الخطر الذي أقدم الناس عليه بتخبطهم و غلو ائهم في التفاخر و العصبيّة.

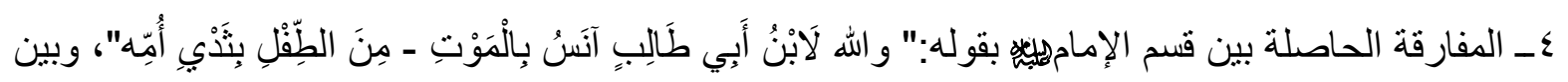

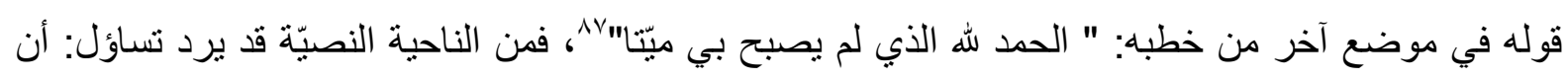
كيف يقسمهليّهُ بحقيقة أنسه بالموت كما يأنس الطفل بثدي أمّه؟!؛ بينما يحمد الله الذي لم يصيّره ميّتًا! في مقام آخرا، وبذلك يجتمع الحمد على الحياة مع الأنس بالموت!؛ على عدِّ الأوَّلِ مشعرًا بحبّه للبقاء والثاني مفيدًا

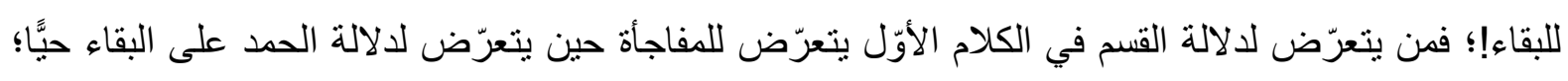
ممّا يترثب عليه كسرًا لأفق التوقّع وخلخلة ذلك التوقع بسبب المفارقة الحاصلة بينهما؛ إلّا أنّ الباحث الأسلوبيّ بإمكانه أن يقّّم تلك الخلخلة، ويعيد نرتيب الدّلالة في تلك المفارقة حين يستذكر فاعليّة السياق في توجيه المعنى، وتوضيح الدلالة؛ فالقسم بأنسه بالموت لديّلجاء في معرض تأكيده في دعوى ردّه بتكذيب الأوهام

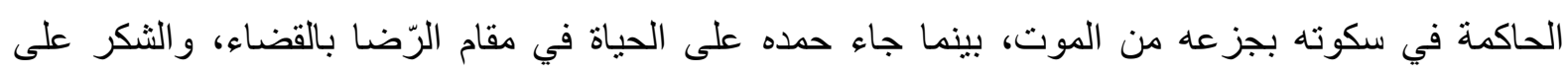

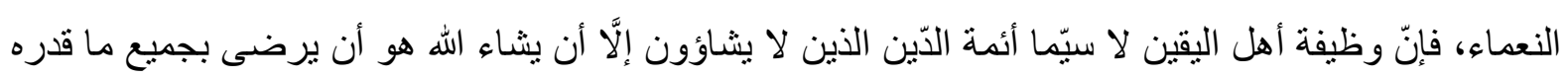

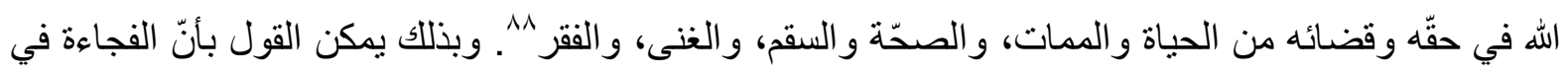

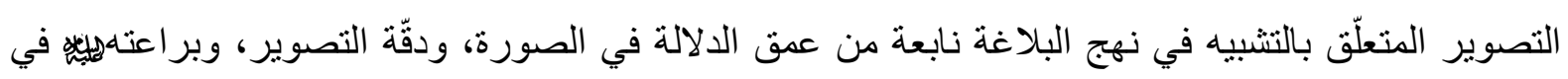
إدهاش المتلقيّ باكتشاف وجوه شبه خفيتت عليه لو لا تعرّضه لذلك البيان، ومعرفته بوجوه شبه جديدة حتّى بين الأطر اف المتباعدة، ممّا لم يقع في حسبانه أنّها قد تربط بين الأشياء؛ ما يجعل الصورة معجزة في تشكيلها

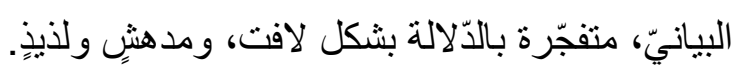

\section{هوامشى البمث:}

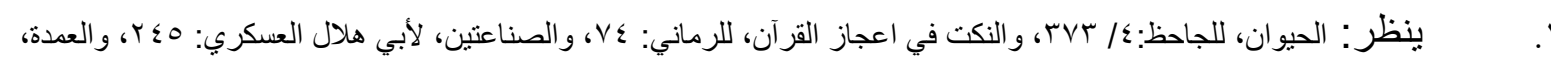

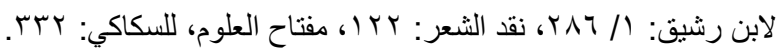

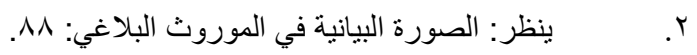

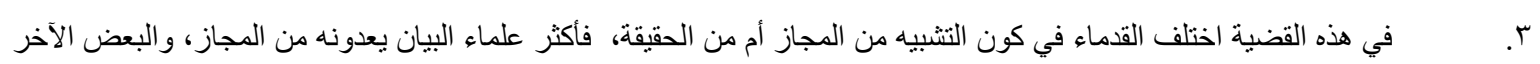

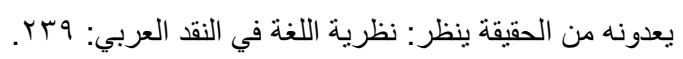

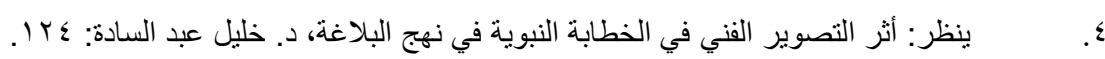




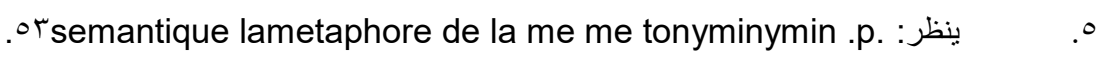

$$
\text { ^. }
$$

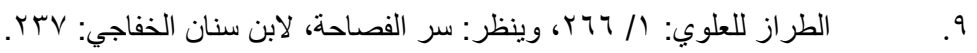

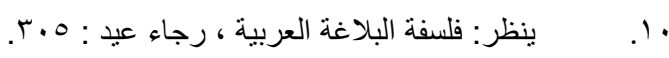

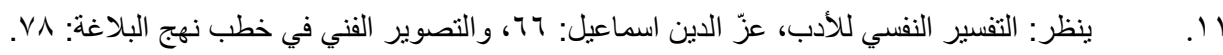

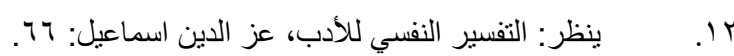

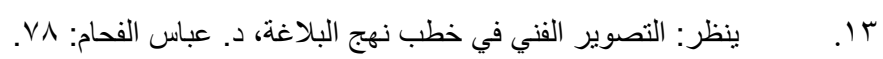

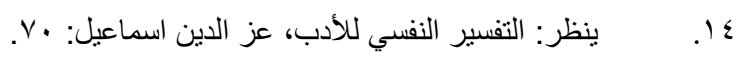

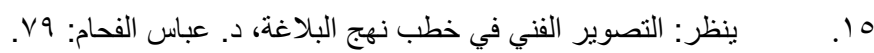

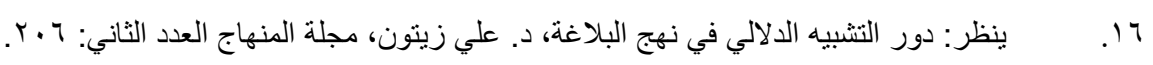

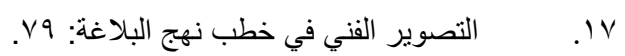

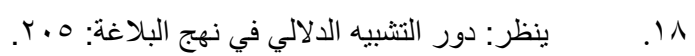

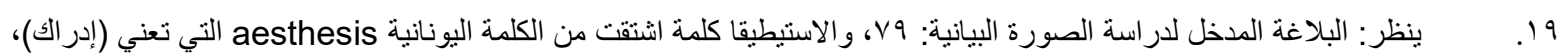
و الاستيطيقا علم الجمال والفن و الذوق، وايضا إبداع وتقدير الجمال، وهو علم يبحث في المحسوسات والمدركات...

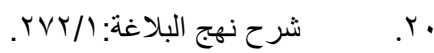

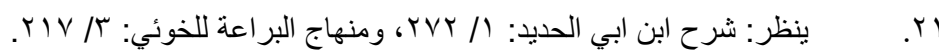

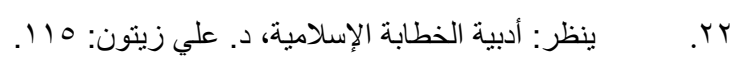

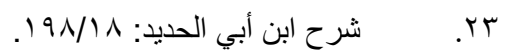

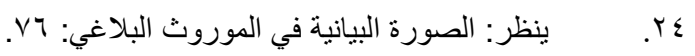

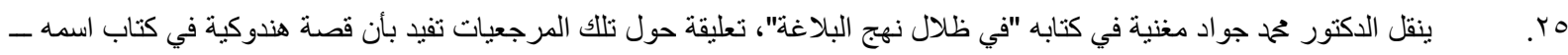
كيف يحيا الإنسان - ويرجع تاريخها إلى أربعة ألاف عام، تشير إلى مرجعيات تتعلق بخلق جنس المرأة المتمثل في حواء عليها السلام، تفسر لنا

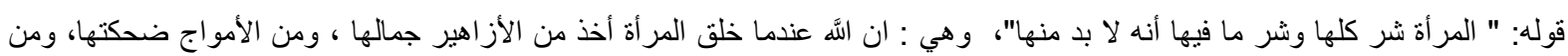
قوس القزح ألو انه، ومن الطيور أغاريدها ، ومن النسيم قبلاته ، ومن الحمل وداعته ، ومن الثعلب مكره ، ومن زخاخ المطر تقلبه، ونسجها كلها لهاه

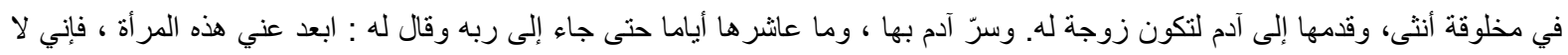

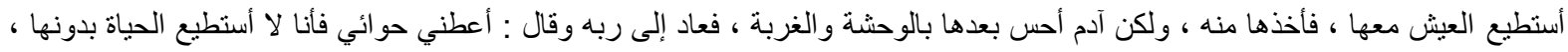

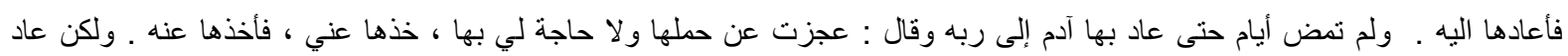

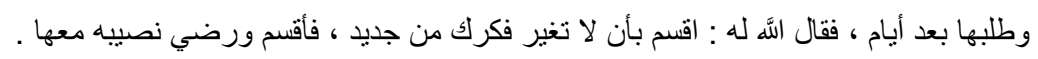

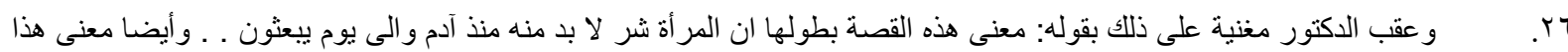

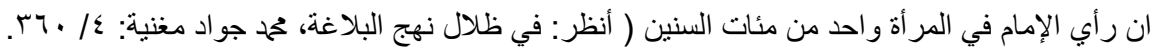

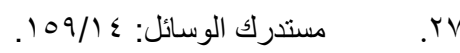

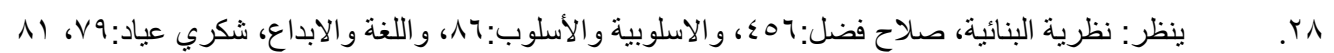

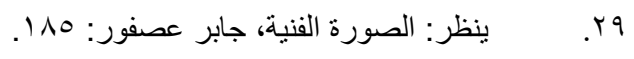

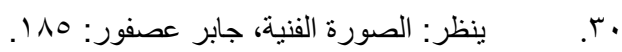



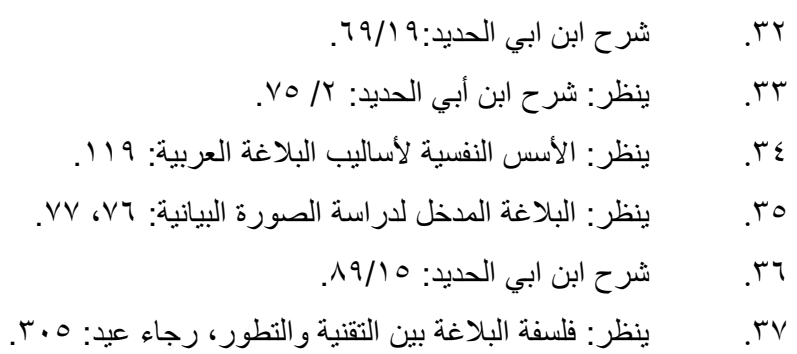




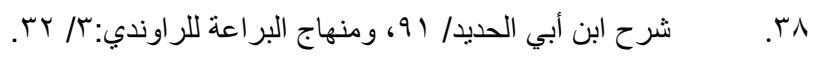

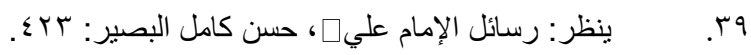

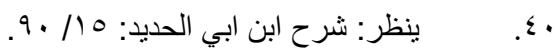

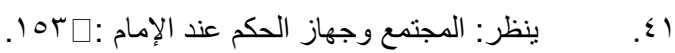

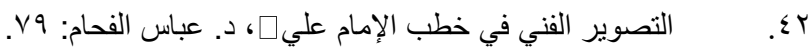

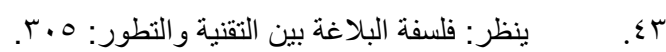

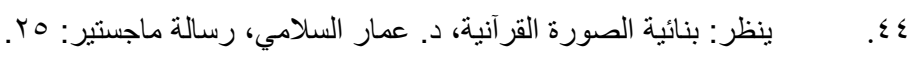

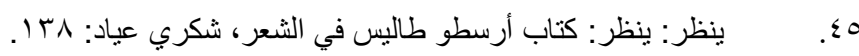

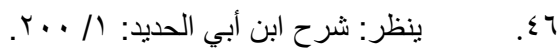

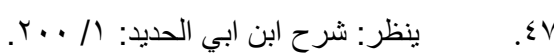

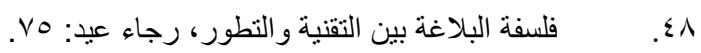

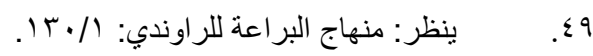

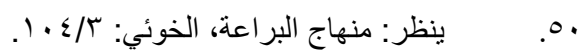

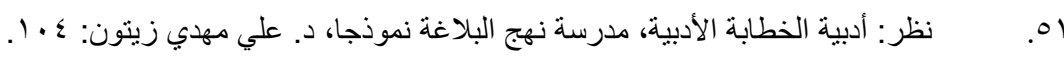

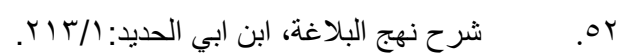

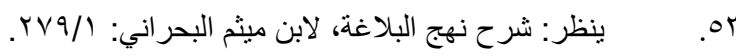

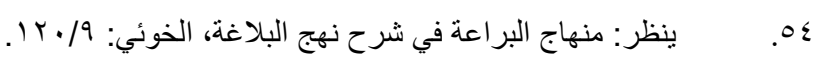

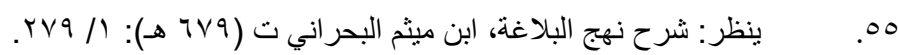

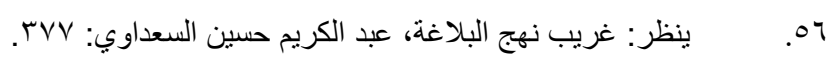

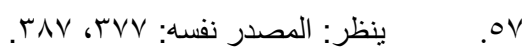

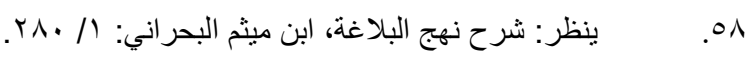

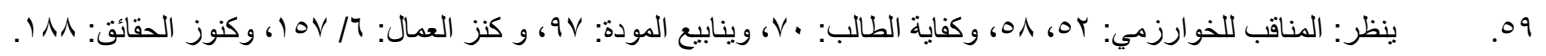

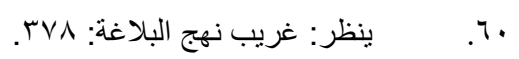

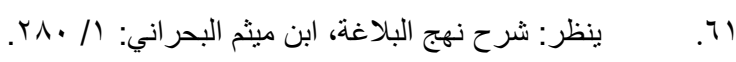

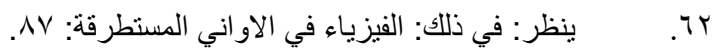

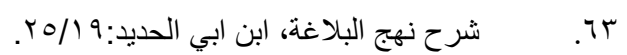

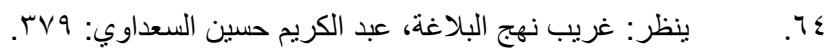

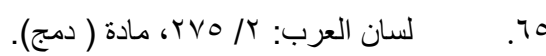

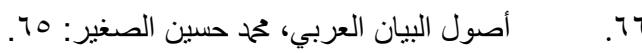

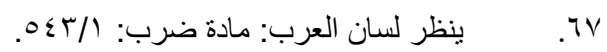

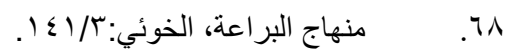

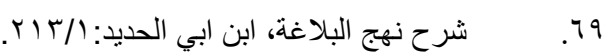

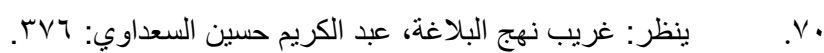

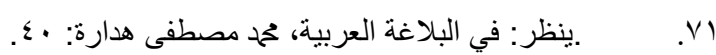

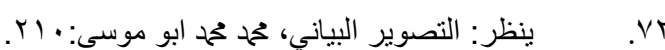

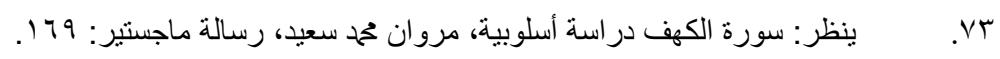

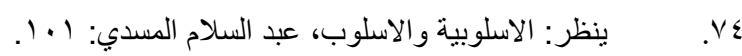

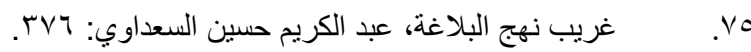

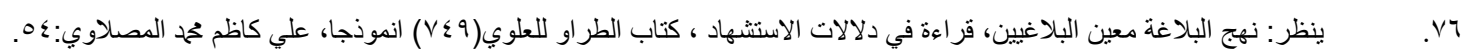

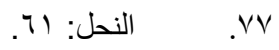

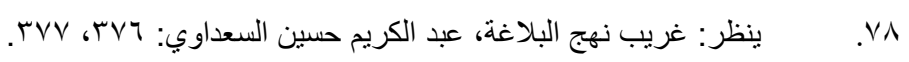

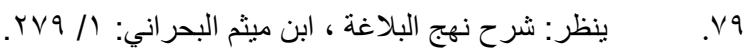




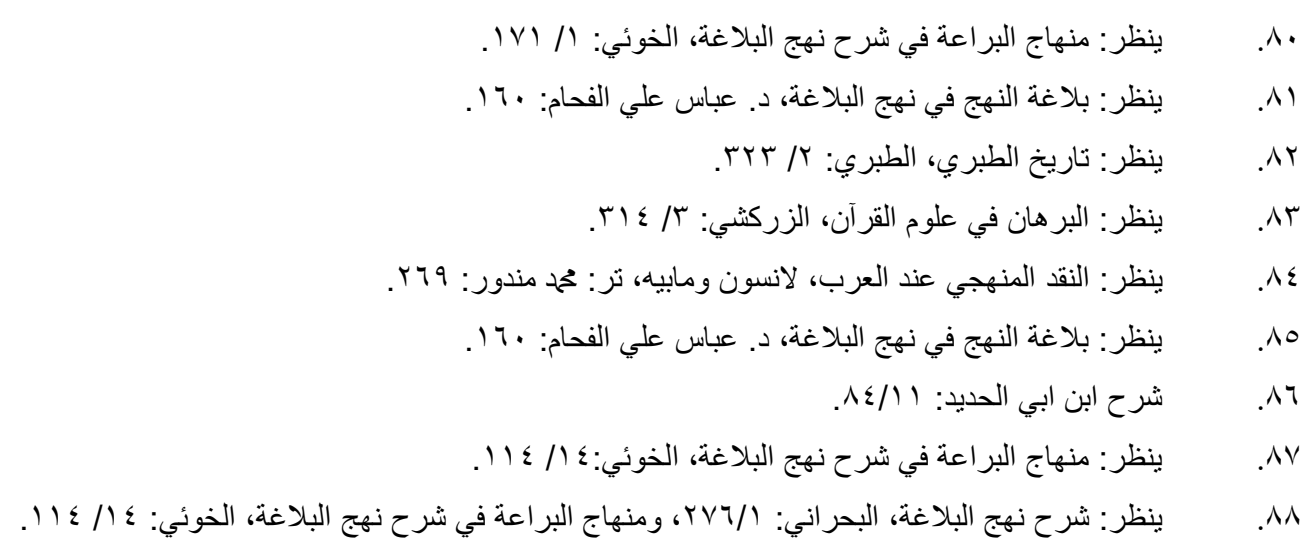

المصادر والمراجع

أثر التصوير الفني في الخطابة النبوية في نهج البلاغة، د. خليل عبد السادة، شهاب جمعة ابراهيخ.

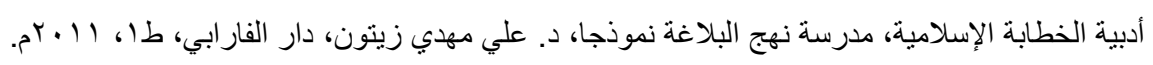

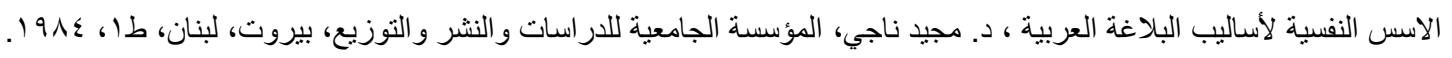

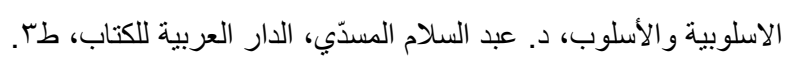

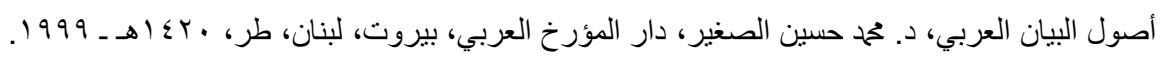

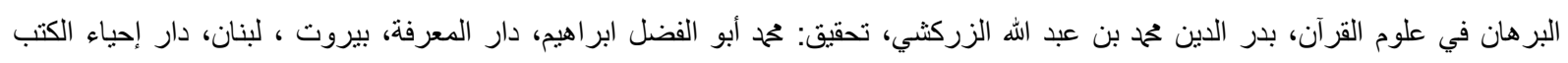



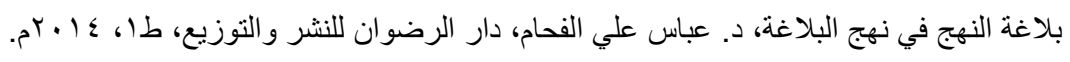

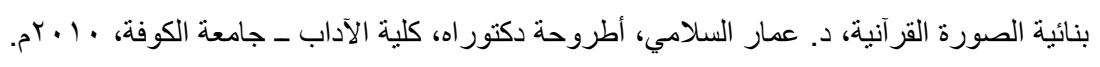

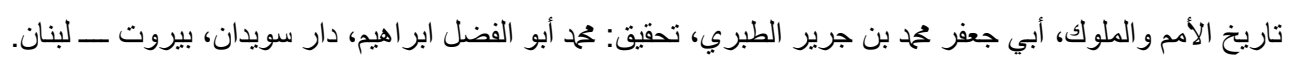

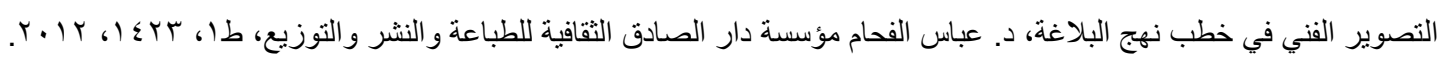

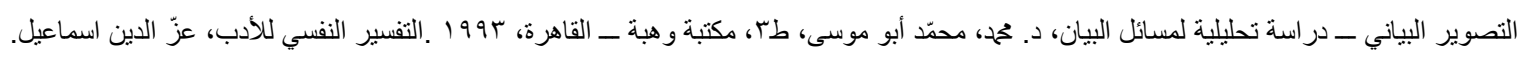

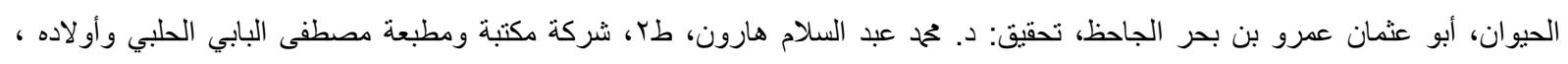

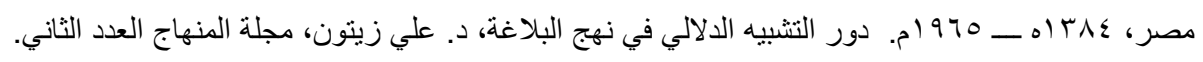

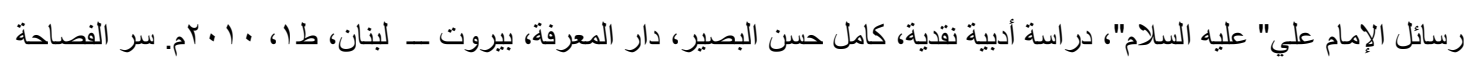

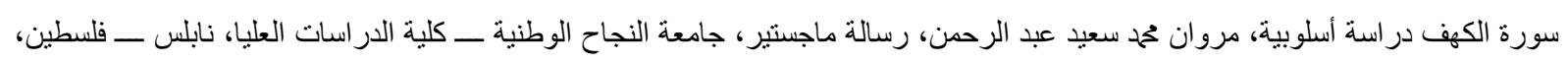

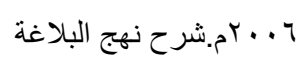

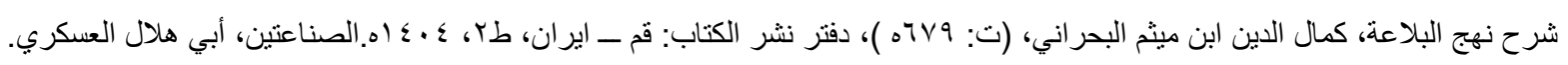

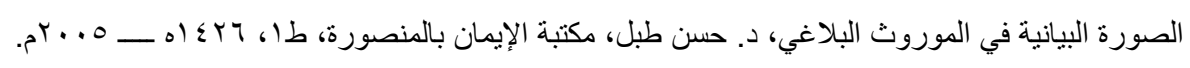

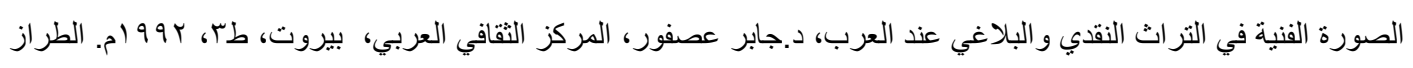

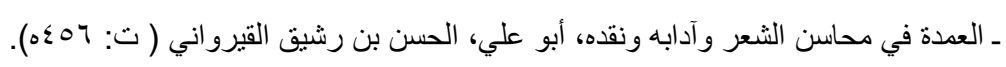

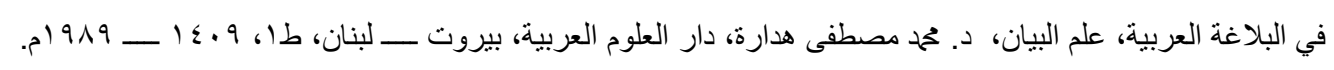



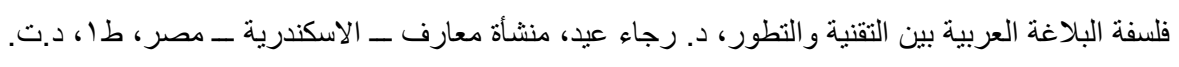

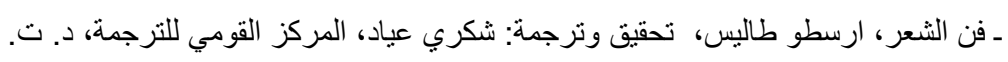

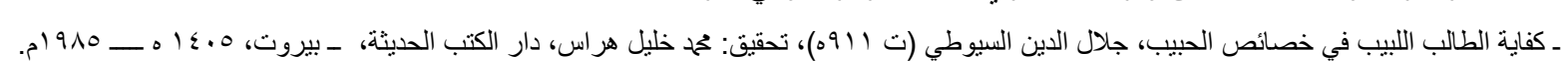



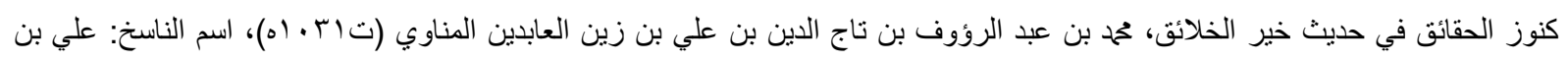

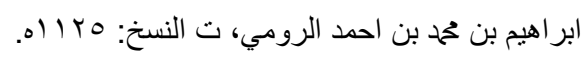

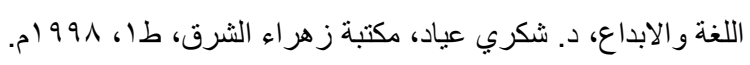

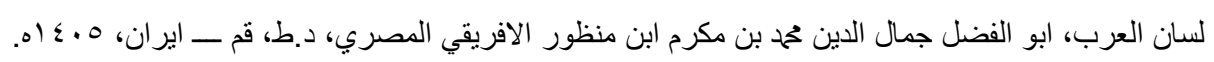

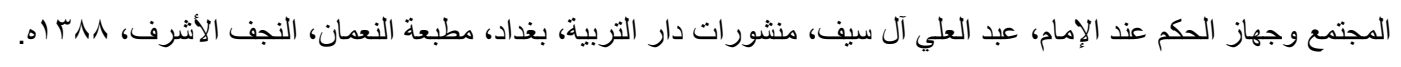


مستدرك الوسائل ومستنبط المسائل، ميرزا حسين النوري الطبرسي (ت . بس (ه)، قم، مؤسسة آل البيت لإحياء التراث.

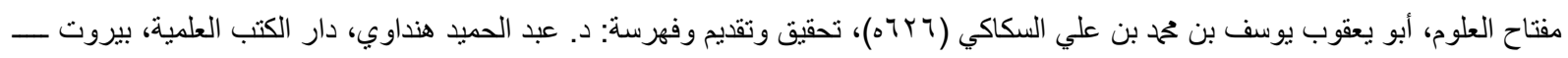

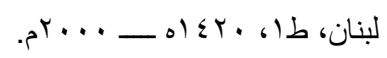

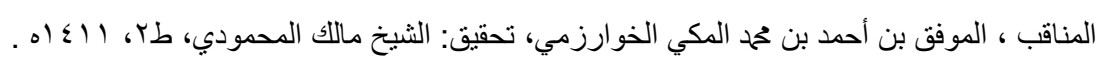



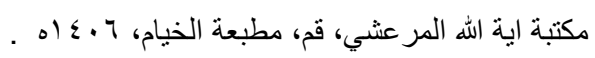
منهاج البراعة في شرح نهج البلاغة، ميرزا حبيب الله الهاثمي الخوئي، تصحيح وتهذيب: السيد ابراهيم الميانجي، طء، منشورات دار الهجرةا

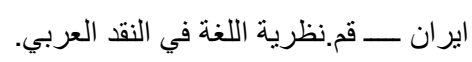

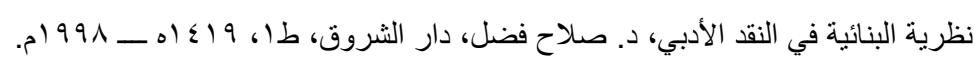

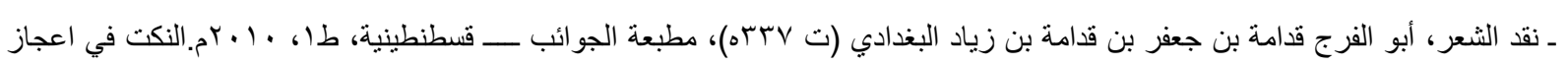
القرآن، الرماني.

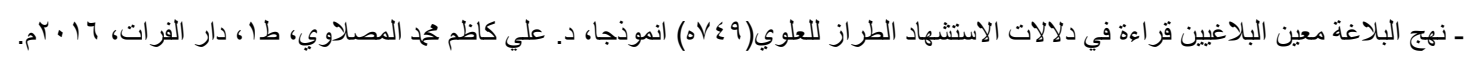

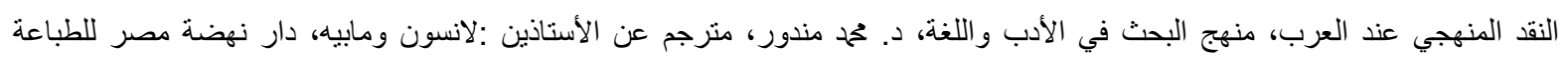
والنشر و التوزيع، 997 (م. 